\title{
Aerosol chemical and optical properties over the Paris area within ESQUIF project
}

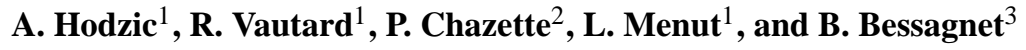 \\ ${ }^{1}$ Laboratoire de Météorologie Dynamique, Institut Pierre-Simon Laplace, Palaiseau, France \\ ${ }^{2}$ Laboratoire des Sciences du Climat et de l'Environnement, Institut Pierre-Simon Laplace, Gif sur Yvette, France \\ ${ }^{3}$ Institut National de l'Environnement Industriel et des Risques, INERIS, Verneuil en Halatte, France
}

Received: 21 July 2005 - Published in Atmos. Chem. Phys. Discuss.: 3 January 2006

Revised: 28 June 2006 - Accepted: 24 July 2006 - Published: 8 August 2006

\begin{abstract}
Aerosol chemical and optical properties are extensively investigated for the first time over the Paris Basin in July 2000 within the ESQUIF project. The measurement campaign offers an exceptional framework to evaluate the performances of the chemistry-transport model CHIMERE in simulating concentrations of gaseous and aerosol pollutants, as well as the aerosol-size distribution and composition in polluted urban environments against ground-based and airborne measurements. A detailed comparison of measured and simulated variables during the second half of July with particular focus on 19 and 31 pollution episodes reveals an overall good agreement for gas-species and aerosol components both at the ground level and along flight trajectories, and the absence of systematic biases in simulated meteorological variables such as wind speed, relative humidity and boundary layer height as computed by the MM5 model. A good consistency in ozone and NO concentrations demonstrates the ability of the model to reproduce the plume structure and location fairly well both on 19 and 31 July, despite an underestimation of the amplitude of ozone concentrations on 31 July. The spatial and vertical aerosol distributions are also examined by comparing simulated and observed lidar vertical profiles along flight trajectories on 31 July and confirm the model capacity to simulate the plume characteristics. The comparison of observed and modeled aerosol components in the southwest suburb of Paris during the second half of July indicates that the aerosol composition is rather correctly reproduced, although the total aerosol mass is underestimated by about $20 \%$. The simulated Parisian aerosol is dominated by primary particulate matter that accounts for anthropogenic and biogenic primary particles $(40 \%)$, and inorganic aerosol fraction (40\%) including nitrate (8\%), sulfate $(22 \%)$ and ammonium (10\%). The secondary organic aerosols (SOA) represent $12 \%$ of the total aerosol mass,
\end{abstract}

Correspondence to: A. Hodzic

(hodzic@1md.polytechnique.fr) while the mineral dust accounts for $8 \%$. The comparison demonstrates the absence of systematic errors in the simulated sulfate, ammonium and nitrates total concentrations. However, for nitrates the observed partition between fine and coarse mode is not reproduced. In CHIMERE there is a clear lack of coarse-mode nitrates. This calls for additional parameterizations in order to account for the heterogeneous formation of nitrate onto dust particles. Larger discrepancies are obtained for the secondary organic aerosols due to both inconsistencies in the SOA formation processes in the model leading to an underestimation of their mass and large uncertainties in the determination of the measured aerosol organic fraction. The observed mass distribution of aerosols is not well reproduced, although no clear explanation can be given.

\section{Introduction}

Impairment of air quality in large urban areas is a consequence of our modern society and raises numerous scientific questions (Seigneur, 2005). Recently, attention has particularly been paid to the particulate matter pollution responsible for adverse health effects (Pope et al., 2002) and visibility degradation in large cities, as well as radiative forcing changes (Anderson et al., 2003) at larger scales. The understanding of physical and chemical processes that govern particulate matter pollution requires efforts in both modeling and monitoring domains. During the last 10 years in Europe, an increasing number of sites have been equipped with instruments measuring the particulate matter mass for diameters less than 10 microns $\left(\mathrm{PM}_{10}\right)$. This effort helped to quantify the human exposure of such pollution, but does not help to fully understand the complete physics of aerosols in a large city. This is a result of the large variety of aerosol components themselves: their size, shape, and chemical composition. In order to better document and understand these characteristics and processes, air quality models (Seigneur, 2001;

Published by Copernicus GmbH on behalf of the European Geosciences Union. 
Zhang et al., 2004) that include sophisticated parameterizations of gas-phase and aerosol chemistry, physics, emission, transport and deposition have been designed.

Such models are used in various applications: The assessment of air pollution impacts and the elaboration of air management policies (Kyle et al., 2002), as well as routine daily forecasts. The performance and limits of aerosol modes still need to be evaluated. Up to now, the current chemistry-transport models (CTMs) have been extensively tested against gaseous species and aerosol total concentration observations, but the evaluation of the aerosol components is largely incomplete especially at the local scale. At the global scale, model performances in simulating the emission sources of aerosol and their long-range transport have been assessed within several experimental campaigns such as INDOEX (Indian Ocean Experiment, e.g., Krishnamurti et al., 1998; Collins et al., 2001). At the regional scale, several long-term evaluations of the modeled aerosol composition over Europe have been performed (Hass et al., 2003; Schaap et al., 2004b; Bessagnet et al., 2004) using EMEP (http://www.emep.int/) air quality measurements. A recent study (Hodzic et al., 2006a) also reported the results of the use of satellite data to assess the model performances in simulating wide particulate pollution episodes over Europe. At local scale, the routine measurements that provide aerosol mass concentrations $\left(\mathrm{PM}_{10}\right.$ and $\left.\mathrm{PM}_{2.5}\right)$ at the ground level are largely insufficient to verify the simulated aerosol chemical, size and mass distribution, its vertical distribution and optical properties. Only intensive measurement campaigns offer such possibilities.

Several intensive field observations that inter-relate the chemical, physical and optical properties of aerosols have been carried out in urban areas (e.g., Hering et al., 1997; Han et al., 2002; Baertsch-Ritter et al., 2003; Cousin et al., 2005). However, the results of simultaneous model evaluations for these aerosol properties have rarely been reported, especially over a large urban area such as Paris city.

In this article, we use the aerosol intensive measurements taken during the ESQUIF (Air Pollution Over the Paris Region) project (Menut et al., 2000; Vautard et al., 2003b) in order to evaluate the skill of an urban-scale chemistrytransport model, CHIMERE (Bessagnet et al., 2004; Hodzic et al., 2005), in simulating aerosol pollution episodes over the Paris region. The ESQUIF experiment offers an exceptional framework to better understand processes leading to air pollution episodes in urban areas and to assess model performances against observations. As the main goal of the campaign is to investigate photo-oxidant pollution, intensive observation periods (IOPs) were performed mostly during summer (summers 1998 to 2000). These are generally 1 to 3 day long periods. The numerous results on the gas-phase pollution measurements and modeling have been reported in Vautard et al. (2003a, b), Beekmann and Derognat (2003), Derognat et al. (2003). The aerosol evolution has been extensively documented only during two pollution episodes around 19 and 31 July 2000. The available data set includes both ground-based measurements of the aerosol chemical composition and airborne measurements of aerosol number concentrations and its vertical distribution across the Paris region. A recent publication (Chazette et al., 2005) presented the optical characteristics of the urban aerosol during the campaign.

In this article, the simulation of the latter two IOPs is carried out with the CHIMERE model in order to examine its ability to describe the aerosol chemical and optical characteristics as well as the aerosol three-dimensional structure. Measurements and model simulations are described in Sects. 2 and 3, respectively. In Sect. 4, the chemical and meteorological conditions are presented and the ability of the model to simulate meteorological parameters during the pollution episodes is evaluated. The comparison results on the aerosol composition, its optical properties and vertical distribution are discussed in Sect. 5. Section 6 contains a summary and a conclusion.

\section{Observations during summer 2000}

Within the ESQUIF project an exhaustive set of dynamical, optical and chemical (gas-phase and aerosol pollutants) observations performed using both ground based and airborne measurements has been built. A detailed description of the data set and instruments is given in Chazette et al. (2005). In this section we briefly recall measurement methods and data sets used in this study.

\subsection{Airborne measurements}

The airborne measurements used in this study were performed aboard the French aircraft Fokker 27/ARAT operated by the technical division of INSU (Institut National des Sciences de l'Univers), the IGN (Institut Géographique National) airborne staff and the Laboratoire des Sciences du Climat et de l'Environnement. Only two flights were performed because of flight restrictions over the city of Paris, and flight plans were established depending on the meteorological conditions. The flight tracks and the spatial distribution of the $\mathrm{PM}_{10}$ concentrations are shown in Fig. 1. Two flight altitudes were considered depending on the measured variables. In-situ measurements of meteorological parameters and pollutant concentrations were performed within the mixed layer (PBL) at the flight altitude in the range 800$1300 \mathrm{~m}(900 \mathrm{hPa}$, indicated in gray color on Fig. 1), while lidar measurements of the aerosol vertical distribution were performed at $4200 \mathrm{~m}(600 \mathrm{hPa}$, indicated in yellow color on Fig. 1) above sea level. The ARAT was equipped with the backscatter lidar LEANDRE 1 to document the atmospheric reflectivity at $532 \mathrm{~nm}$ and $1064 \mathrm{~nm}$ in the lower troposphere (Chazette et al., 2005). 

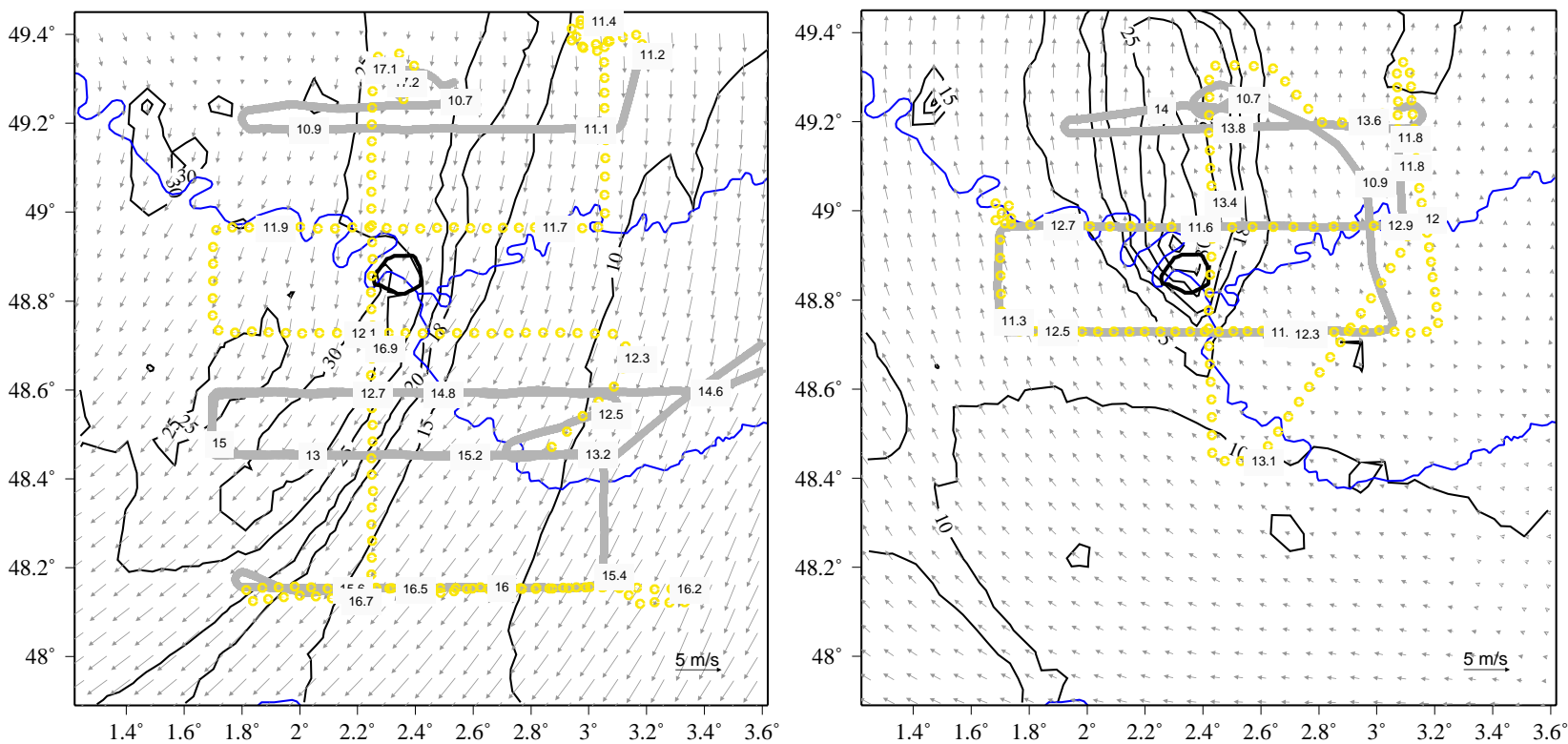

Fig. 1. Modeled $\mathrm{PM}_{10}$ concentrations $\left(\mu \mathrm{g} / \mathrm{m}^{3}\right.$ ) and wind fields (vector at bottom right is $5 \mathrm{~m} / \mathrm{s}$ ) at the surface on 19 (left) and 31 (right) July 2000 at 15:00 UTC. Flight patterns and flight hours are also indicated. The gray and yellow lines refer to the flight altitude of $\sim 900 \mathrm{~m}$ above mean sea level (MSL) and $\sim 4200 \mathrm{~m}$ m.s.l., respectively. The aircraft crossed the center of the plume twice on 19 July at 13:00 and 15:00 UTC, and once on 31 July at 14:00 UTC (see text for details). The city of Paris, crossed by the Seine river (blue color), is represented in the center of the map.

On 19 July, ARAT flight was performed at 10:3013:30 UTC and 14:30-17:30 UTC. The flight started in the north of Paris $(2.4 \mathrm{E}, 49.2 \mathrm{~N})$ and headed south. Several west/east legs at $900 \mathrm{~m}$ upwind and downwind of Paris were achieved, as well as 2 west/east legs and one south/north leg at an altitude of $4200 \mathrm{~m}$. The aircraft crossed the center of the plume twice at 13:00 and 15:00 UTC. On 31 July, the flight lasted from 10:30 to 14:00 UTC. It performed two low-altitude sampling legs across the plume downwind of Paris and crossed the domain from east to west upwind of Paris. Several high-altitude south/north and east/west samplings were also performed above the plume to measure the aerosol optical properties.

During the flights, measurements of several meteorological parameters and pollutant concentrations were performed with a sampling rate of $1 \mathrm{~s}$. Ozone concentrations were measured using an analyser, designed by Thermo Environmental Instrument INC (USA). The NO analyser is a prototype developed by LSCE for airborne measurements using the chemical-luminescence by $\mathrm{NO}$ and $\mathrm{O}_{3}$ reaction. Automatic corrections for temperature, pressure and flow rate are made by software. Data are collected by an external microcomputer on a $1 \mathrm{~s}$ basis through a RS232 connection together with the other on-board measurements. Calibrations were performed before and controlled after the campaign with a 49PS calibration instrument designed by Thermo Environmental Instrument for ozone, and with calibrated gases for the nitrogen oxide. The measurement accuracies are $2 \mathrm{ppbv}$ and 24 pptv for $\mathrm{O}_{3}$ and NO, respectively. The detection limits are equal to the given measurement accuracies thus permitting the determination of the pollution level without ambiguity.

The total aerosol number concentration of aerosol particles with diameters ranging from 0.01 to $3 \mu \mathrm{m}$ was obtained from the 3022A CPC TSI ${ }^{\circledR}$ model particle counters. These counters detect all particles within a diameter size range from 0.007 to $3 \mu \mathrm{m}$, with a $100 \%$ efficiency for $0.02 \mu \mathrm{m}$. Particle concentrations are retrieved with a relative uncertainty of $5 \%$ (Chazette et al., 2005).

\subsection{Ground based measurements}

The aircraft measurements were completed by a set of ground-based measurements performed using the Mobile Aerosol Station (MAS) operated by LSCE (Chazette et al., 2005). Size-resolved aerosol was collected using a 13 stage DEKATI cascade impactor (http://www.dekati.com). It operated at ambient temperature and relative humidity. This instrument samples the particles with diameters between $0.03 \mu \mathrm{m}$ and $10 \mu \mathrm{m}$. Losses within the impactor are less than $0.5 \%$ for particles larger than $0.1 \mu \mathrm{m}$ and relatively stable throughout the size range. For particles smaller than $0.1 \mu \mathrm{m}$, losses start to increase rapidly. The sampling was performed during day- and night-time (07:00 to 18:00 UTC) periods. 


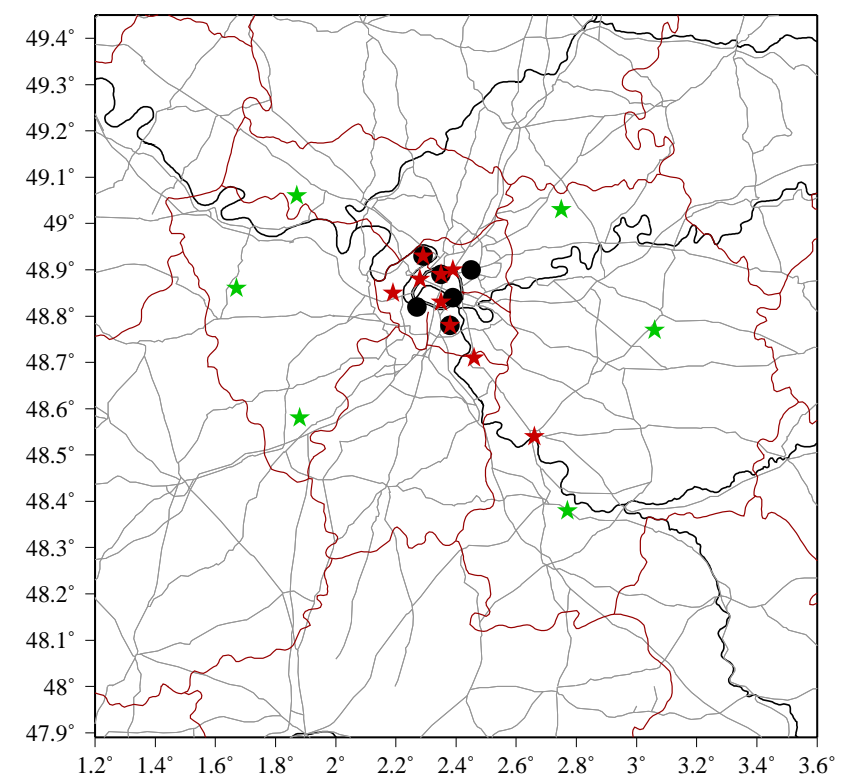

Fig. 2. AIRPARIF monitoring network over the Ile-de-France area. Main roads and the contour of the city of Paris are represented. Heavy dots and stars indicate the location of the $\mathrm{PM}_{10}$ and ozone (urban in red, rural in green) monitoring stations used in this study.

The inorganic fraction $\left(\mathrm{SO}_{4}^{-}, \mathrm{NO}_{3}^{-}, \mathrm{Cl}^{-}, \mathrm{NH}_{4}^{+}, \mathrm{Ca}^{++}, \mathrm{Na}^{+}\right.$, $\mathrm{K}^{+}, \mathrm{Mg}^{++}$) was measured by ion chromatography.

The carbonaceous aerosol fraction was collected using glass fiber filters (Chazette and Liousse, 2001, and references in there). The thermal method was applied for the separation and analysis of black (BC) and organic (OC) carbon aerosol components. The determination of particulate organic matter (POM) concentrations is also affected by the POM content of the non- $\mathrm{C}$ atoms $(\mathrm{H}, \mathrm{O}, \mathrm{N}$, etc), which is currently not measured. To account for these atoms, correction ratios between 1.2 and 1.7 are generally used (Hegg et al., 1997; Turpin et al., 2000). In this study the organic matter observed concentrations are estimated by multiplying organic carbon concentrations by 1.3 (Chazette and Liousse, 2001), although this factor is variable for different aerosol types. The large uncertainties involved in POM concentrations determination must be kept in mind in the discussion.

In addition to the ESQUIF campaign measurements, the routine ground observations of $\mathrm{O}_{3}, \mathrm{PM}_{10}$ and $\mathrm{NO}_{Y}$ from the AIRPARIF network have been considered in this study. The location of measurement sites are displayed on Fig. 2. The typology of the AIRPARIF stations (urban, rural, etc.) is based on the site location and environmental criteria according to the national classification of air quality monitoring sites.

\section{The aerosol chemistry-transport model}

\subsection{Model configuration}

The model used in this study, CHIMERE, has been developed at the French Institute Pierre-Simon Laplace (IPSL), the Laboratoire Interuniversitaire des Systèmes Atmosphériques (LISA) and the Institut National de l'Environnement industriel et des RISques (INERIS). It is a 3-D chemistry-transport model that simulates gas-phase chemistry (Schmidt et al., 2001; Vautard et al., 2003a), aerosol formation, transport and deposition at the European scale (Bessagnet et al., 2004; Vautard et al., 2005; Hodzic et al., 2006a) and urban scales (Hodzic et al., 2004, 2005). A detailed description of the model is presented in previous references and on the web site http://euler.lmd.polytechnique.fr/chimere. Here we briefly describe the main model characteristics and its configuration for this study.

The chemical mechanism accounts for 44 gaseous species and 7 aerosol compounds including the secondary inorganics sulfate, nitrate, ammonium, the anthropogenic and biogenic secondary organic aerosol (SOA) and water. Because of the lack of speciation in anthropogenic emission inventories, all primary emissions are put into a single compound, the primary particulate matter (PPM). Recently, Vautard et al. (2005) introduced the transport of desert dust from lateral boundary conditions and simplified parameterizations of the local (within Europe) emission of wind-blown biogenic particulate matter, whose associated compounds are also put into the PPM class. Secondary organic aerosols (SOA) are formed by condensation of biogenic and anthropogenic hydrocarbon oxidation products and partitioned between the aerosol and gas phase through partition coefficients (Pankow, 1994). Heterogeneous chemical processes onto particles and fog droplets (nitrate production) and a simplified sulphur aqueous chemistry (sulfate production) are accounted for in the model. The thermodynamic equilibrium is computed using the ISORROPIA model (Nenes et al., 1998).

The aerosol population is represented using a sectional approach, considering 6 size bins geometrically spaced from $10 \mathrm{~nm}$ to $40 \mu \mathrm{m}$ diameter in the standard configuration. Dynamical processes influencing aerosol population are also taken into account. New particles are formed by nucleation of $\mathrm{H}_{2} \mathrm{SO}_{4}$ (Kulmala et al., 1998) and grow as a result of the coagulation and condensation of semi-volatile species on preexisting particles followed by the coagulation processes. Finally, aerosols can be removed by dry deposition (Seinfeld and Pandis, 1998) and wet removal (Guelle et al., 1998; Tsyro 2002). Particles can be scavenged either by coagulation with cloud droplets or by precipitating drops.

In the present application, the simulations are performed at the local scale using a one-way nesting procedure: a coarse simulation with a $50 \mathrm{~km}$ resolution over Western Europe is first carried out. Boundary conditions for this regional simulation are monthly climatologies of the LMDZ/INCA global 
chemistry-transport model for gaseous species (Hauglustaine et al., 2004) and monthly climatologies of the GOCART model for aerosol species (Ginoux et al., 2001), with corrections for mineral dust as proposed by Vautard et al. (2005). The GOCART model provides a spectral size distribution for mineral dust, hydrophobic and hydrophilic organic carbon (OC), hydrophobic and hydrophilic black carbon (BC), and sulfate particles ranging from 0.2 to $12 \mu \mathrm{m}$ in diameter which is interpolated to the CHIMERE aerosol size representation. To account for the sporadic nature of dust emissions we use, as dust boundary forcing, concentrations three times smaller than the average GOCART values (Vautard et al., 2005).

Concentrations from the regional simulation then provide hourly boundary conditions to a higher resolution simulation, performed over a $180 \times 180 \mathrm{~km}$ area centered on Paris with a $6 \times 6 \mathrm{~km}$ horizontal resolution (see Fig. 1). Vertical resolution contains 8 hybrid sigma-pressure levels extending up to $500 \mathrm{hPa}$, which covers the boundary layer and the lower half of the free troposphere. The model calculations are performed with $2.5 \mathrm{~min}$ chemical and $10 \mathrm{~min}$ physical time steps for the small scale domain. The numerical solver is adapted from the second-order TWOSTEP algorithm (Verwer, 1994), which uses the Gauss-Seidel iteration scheme.

The meteorological input fields are taken from the MM5 mesoscale model (Dudhia et al., 1993), forced by ECMWF (European Center for Medium-Range Weather Forecasts) global-scale analyses. As in Hodzic et al. (2005), the latest AIRPARIF emission inventory is used for gaseous and particulate matter at urban scale.

\subsection{Model simulations}

In this study, the model is run from 13 July to 1 August 2000 at both regional and urban-scale simulations. A prior spin-up 5 day simulation is performed to initialize the model from initial climatological values. Two model simulations with different configurations are carried out. In the first case (R1), devoted to the assessment of the aerosol chemical composition, the number of aerosol sections is increased from 6 to 11 bins and from $10 \mathrm{~nm}$ to $20 \mu \mathrm{m}$ in diameter. In the second case (R2), devoted to the study of the aerosol optical properties and their vertical distribution, vertical resolution is increased to twenty sigma-pressure levels. Therefore, the $\mathrm{R} 1$ simulation is evaluated against ground-based data, while the R2 simulation is used for the comparison with airborne observations as it is expected to be more accurate in higher altitudes. For comparison with measurements, the simulated parameters are spatially and temporally interpolated along flight trajectories.
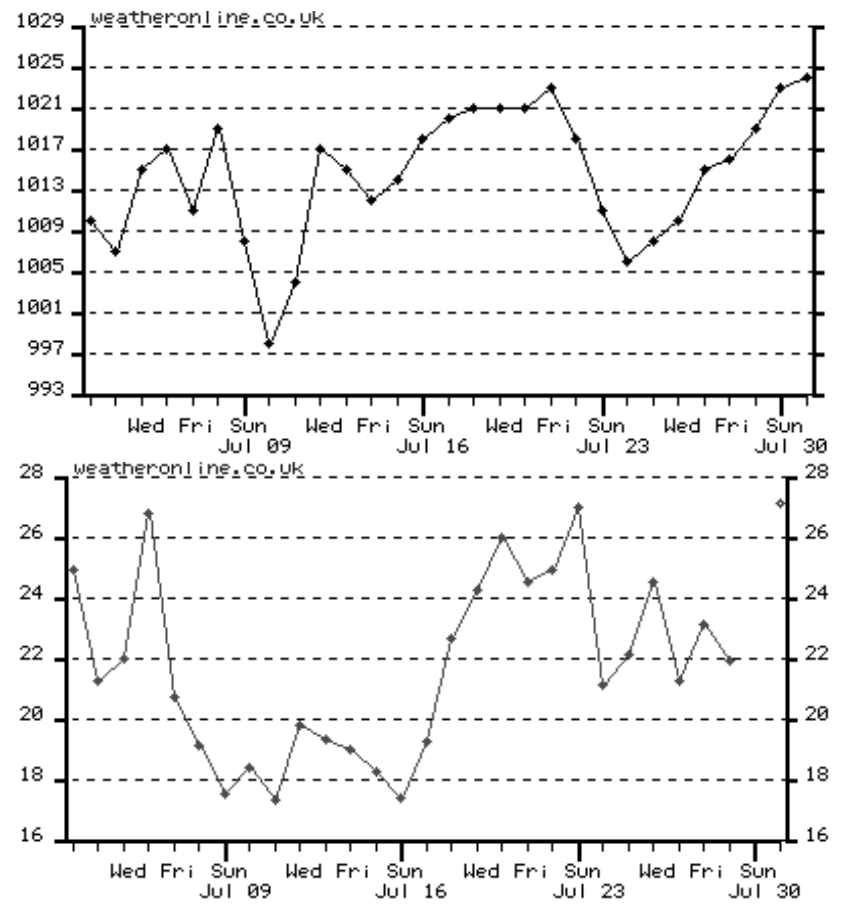

Fig. 3. Atmospheric pressure (hPa) and maximal temperatures $\left({ }^{\circ} \mathrm{C}\right)$ observed at Paris/Orly in July 2000 (courtesy to http://www. weatheronline.co.uk).

\section{Chemical and meteorological conditions}

\subsection{Synoptic weather during the second half of July 2000}

The second half of July 2000 is characterized by relatively high pressure systems lasting from 15 to 23 July with maximal temperatures in the range 17 to $27^{\circ} \mathrm{C}$ in the south of Paris (Fig. 3). These stable atmospheric conditions are replaced by the variable weather on 24 July because of the succession of two low-pressure systems over France bringing some rain on 24 and 26 July (Fig. 7). Weather conditions improved progressively from 27 July with the increase of pressure and temperature. However, the lack of long-lasting stagnation inhibited the development of large-scale pollution episodes.

\subsection{Pollutant concentrations during the period}

Figure 4 shows hourly $\mathrm{O}_{3}, \mathrm{PM}_{10}$ and $\mathrm{NO}_{Y}$ concentrations observed by the AIRPARIF network (and simulated by CHIMERE, see discussion in Sect. 5.1) during July 2000 at urban and rural stations. During July, moderately high ozone concentrations are observed from 18 to 20 and on 31 July with ozone peaks greater than $60 \mathrm{ppbv}$ in the afternoon.

The $\mathrm{NO}_{\mathrm{y}}$ concentrations, on average over urban stations, vary from an afternoon value of about $20 \mathrm{ppbv}$ to morning peak traffic-hour values of $100-150 \mathrm{ppbv}$ in anticyclonic days. On other more windy and rainy days, morning 
URBAN Stations

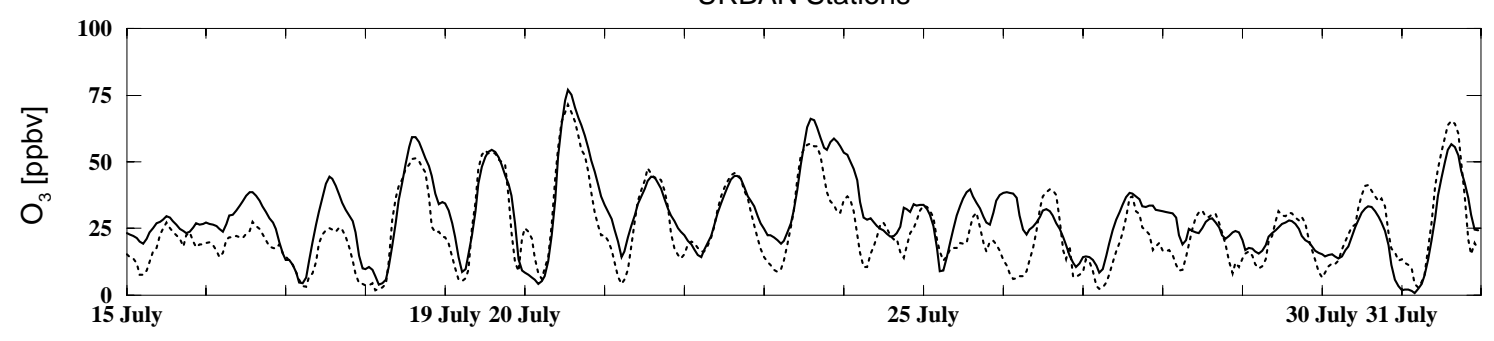

RURAL Stations
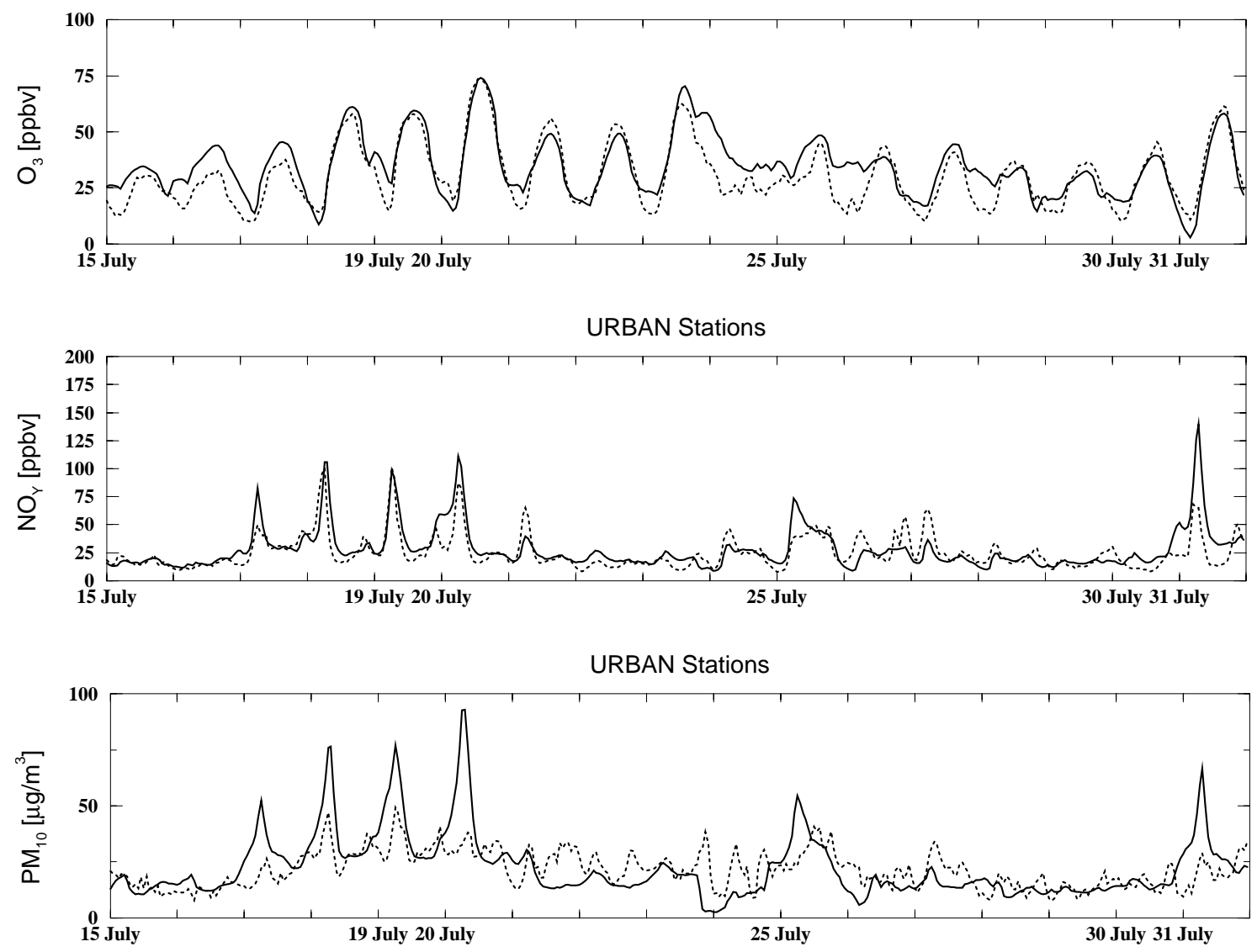

Fig. 4. Major pollutant concentrations as observed by air quality stations of AIRPARIF network (dotted line) and simulated by CHIMERE model (full line) from 15 to 31 July 2000.

concentrations remain much weaker (20-50 ppbv). Note that the evening traffic-hour emission peak does not produce a concentration peak because it occurs at a time when boundary layer mixing is still strong.

The accumulation of the aerosol load is observed from 18 to 20 and on $31 \mathrm{July}$ with values close to $30 \mu \mathrm{g} / \mathrm{m}^{3}$ in the afternoon and about $50 \mu \mathrm{g} / \mathrm{m}^{3}$ in the morning for $\mathrm{PM}_{10}$. The contrast between morning peak and afternoon minima is not as pronounced as for $\mathrm{NO}_{\mathrm{y}}$. This is a consequence of the fact that the ratio between background $\mathrm{PM}_{10}$ concentration advected into the city, as seen in nighttime concentrations, and production from local emissions is much higher than for $\mathrm{NO}_{\mathrm{y}}$ (as shown for instance by concentrations during the period 17-20 July).

4.3 Meteorological conditions during the episodes of 19 and 31 July 2000

In the following, we focus on pollution episodes of 19 and 31 July as two representative moderate summer pollution episodes over the Paris area. Figure 1 shows the air circulation issued from MM5 and $\mathrm{PM}_{10}$ concentrations simulated by CHIMERE over the Paris area during these episodes (see discussion in Sect. 5). The first episode of 19 July is 
(a)
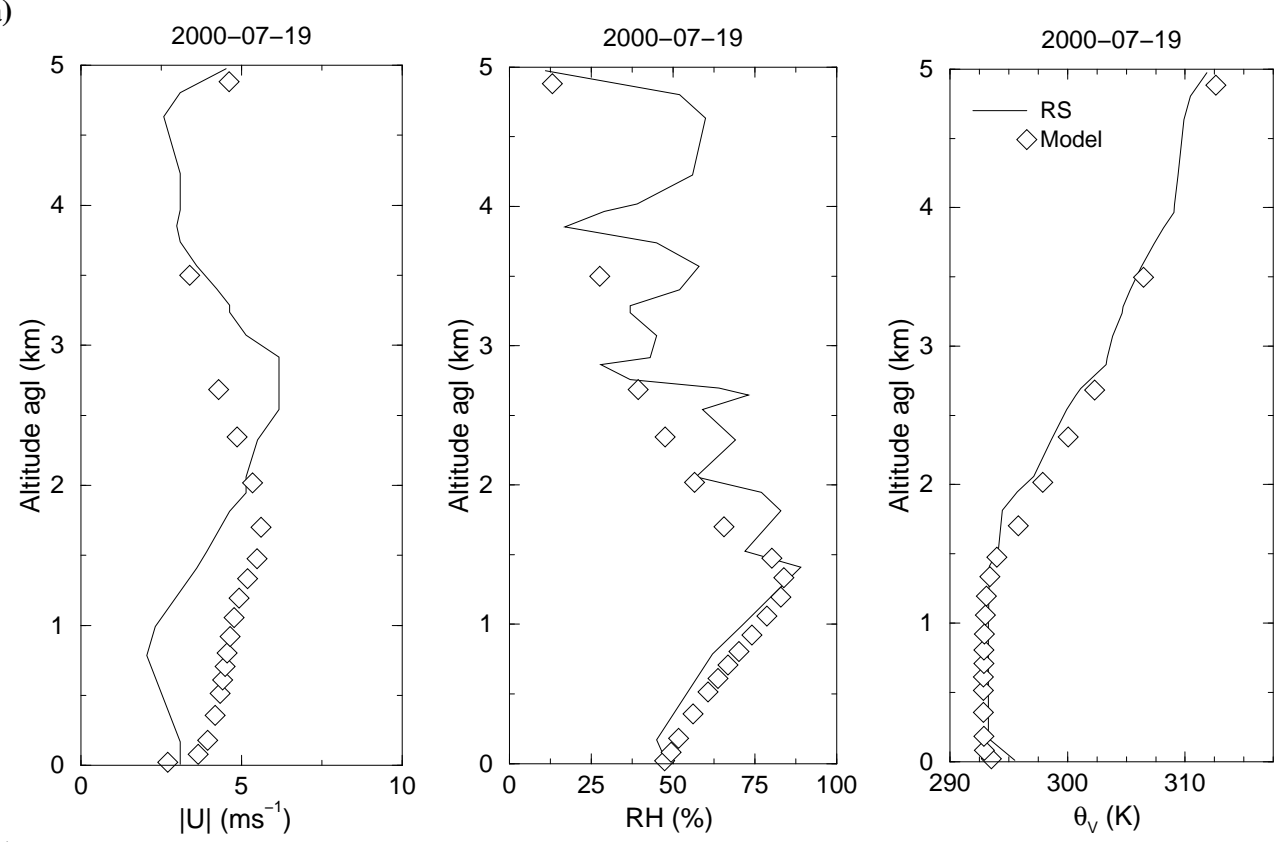

(b)
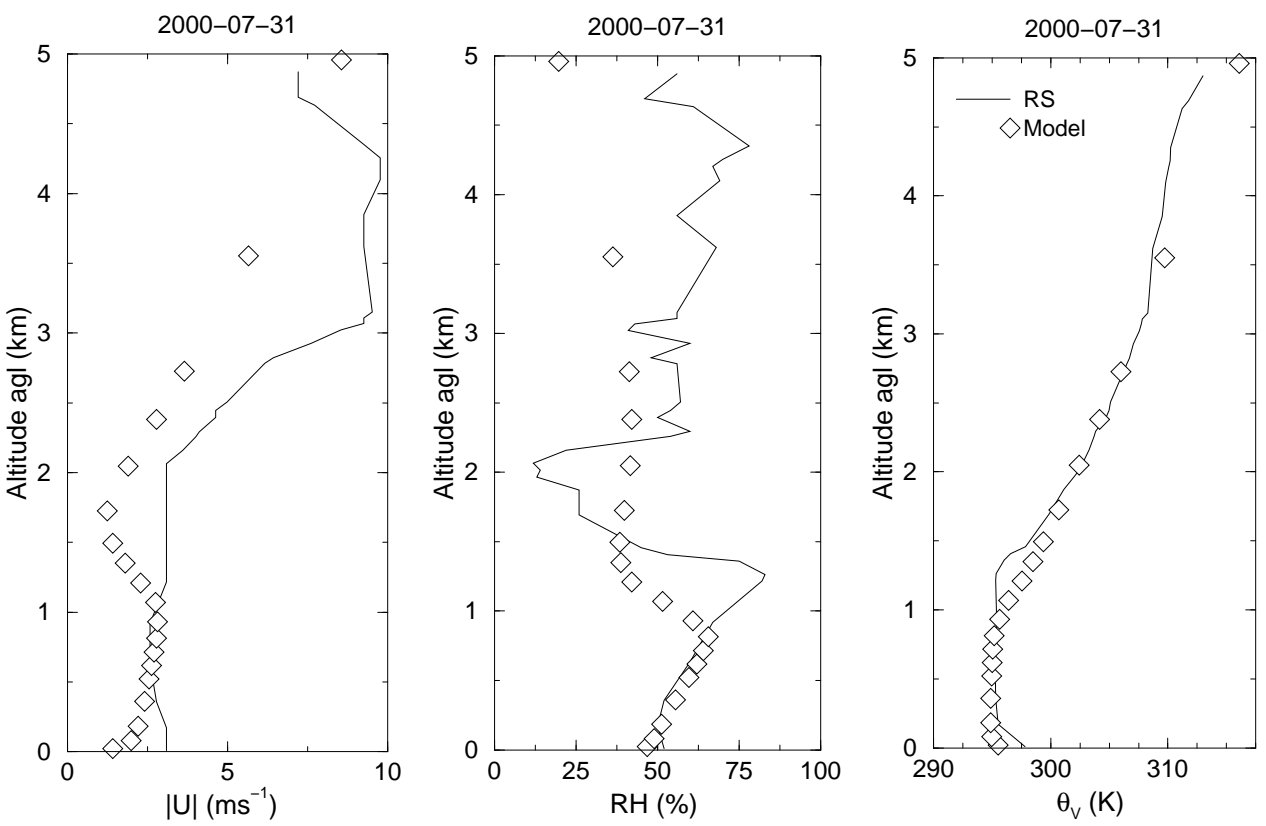

Fig. 5. Vertical profiles of wind speed $(\mathrm{U})$, relative humidity $(R H)$ and potential temperature $\left(\Theta_{V}\right)$ observed by Trappes $\left(48.78^{\circ} \mathrm{N}, 2^{\circ} \mathrm{E}\right)$ radiosoundings (solid line) and simulated by the model (diamonds) on 19 (a) and 31 (b) July 2000.

characterized by a moderate Northeasterly wind $\left(3-5 \mathrm{~ms}^{-1}\right)$ over Paris caused by a high pressure system over Great Britain. In such a synoptic situation, polluted air masses are advected from Northern Europe towards France resulting in higher background ozone and aerosol concentrations than in maritime flow conditions. Maximal temperatures are close to $24^{\circ} \mathrm{C}$ over Paris. The presence of numerous scattered cumulus has been noticed on lidar vertical profiles (Chazette et al., 2005).
During the episode of 31 July, the North of France undergoes stable anticyclonic conditions characterized by weak Southeasterly winds $\left(<3 \mathrm{~ms}^{-1}\right)$ and temperatures greater than $27^{\circ} \mathrm{C}$ favoring the development of a photo-oxidant pollution. Back trajectories computed by Chazette et al. (2005) show that the air mass advected over Paris comes from the Atlantic Ocean and is influenced essentially by local aerosol emission and secondary production. 
a)

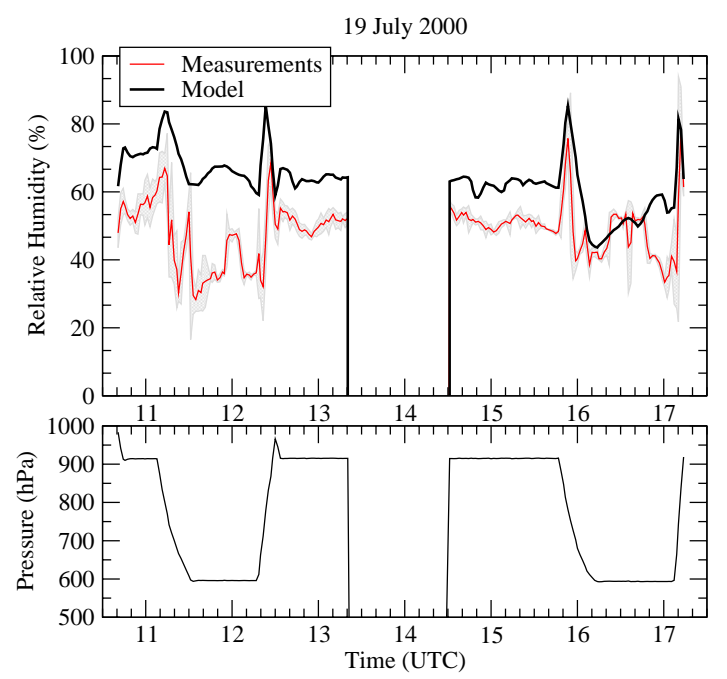

b)

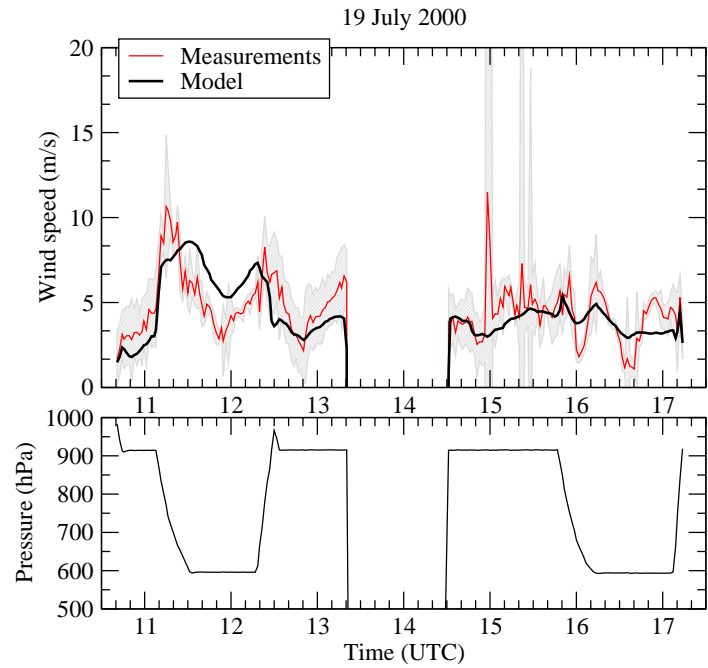

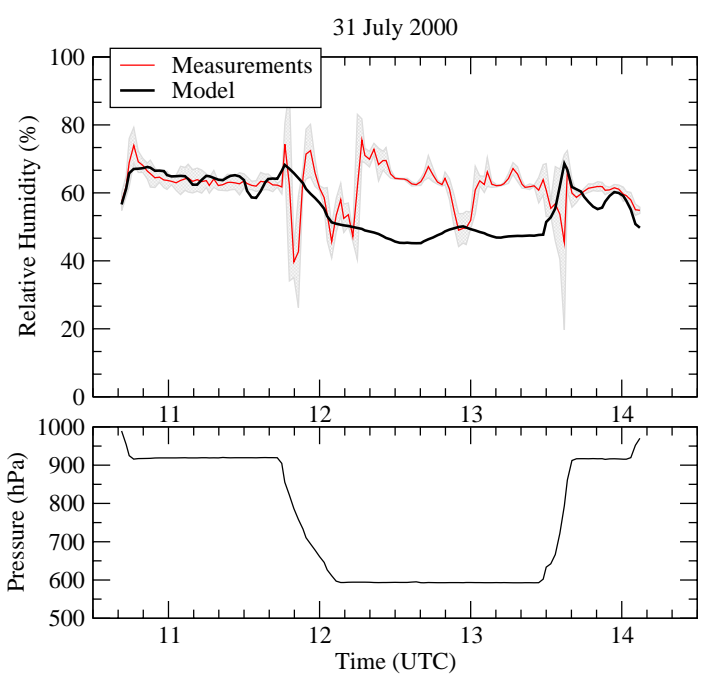

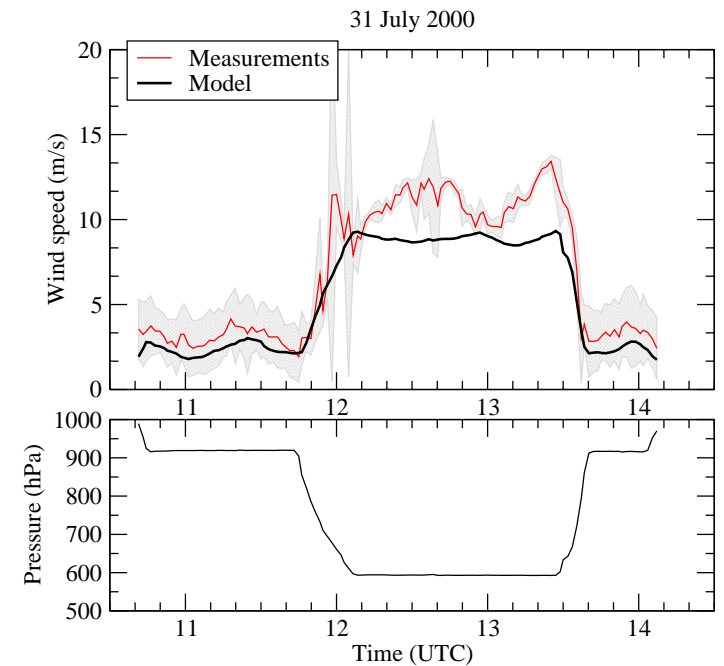

Fig. 6. Relative humidity (a) and wind speed (b) time series as observed (red line) during the ARAT flight and simulated by the model (black line) on 19 and 31 July 2000. The flight altitude is also given in hPa. Observations are 2 min-averaged and the variability is indicated by grey interval.

\subsection{Verification of meteorological simulation}

The meteorological variables such as wind speed and planetary boundary layer (PBL) height are essential parameters that govern pollution dispersion. Thus, before evaluating the CHIMERE chemistry-transport model skill to reproduce aerosol pollutant concentrations, we first examine whether these meteorological variables are correctly reproduced by the MM5 meteorological model during the two pollution events under study.

The three-dimensional thermodynamical structure of the atmosphere in the Paris area was documented by radiosoundings performed by Meteo-France at Trappes site located in the South-west suburb of Paris and by measurements performed aboard the ARAT aircraft. Figure 5 shows vertical profiles of observed and simulated wind speed $\left(\mathrm{ms}^{-1}\right)$, potential temperature $(\mathrm{K})$ and relative humidity $(R H, \%)$. On 19 July, radiosoundings performed at 12:00 UTC indicate wind speed values close to $3 \mathrm{~ms}^{-1}$ within the boundary layer, while MM5 simulations give higher values from 3 to $5 \mathrm{~ms}^{-1}$. On 31 July wind speed is well simulated in the PBL, except for the slight underestimation near the ground. Single wind speed profiles measured by radiosoundings have a poor representativeness within the convective PBL, and therefore the quantitative aspect of the comparison for this parameter does not provide much information. The important fact is 

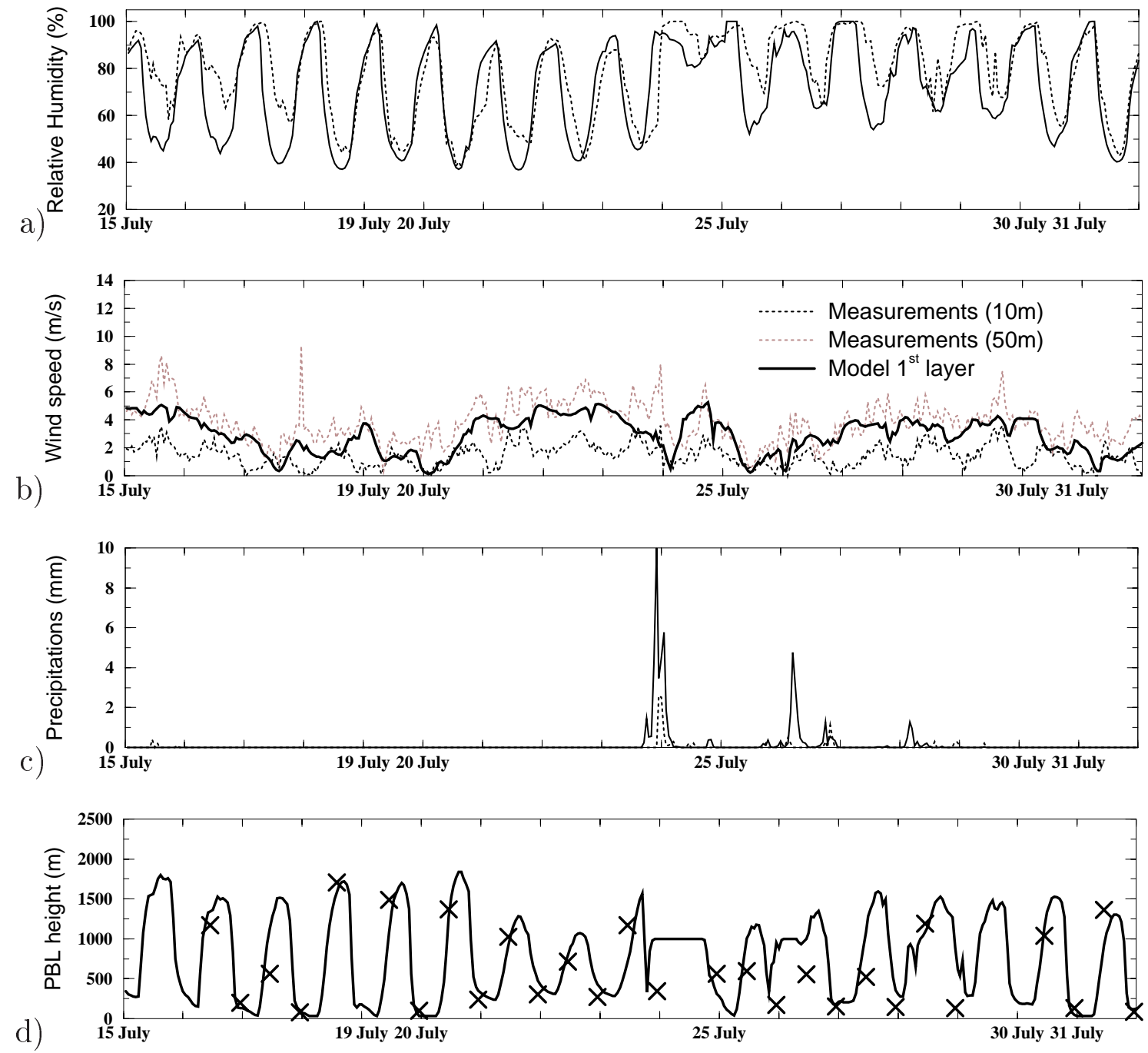

Fig. 7. Time series of meteorological variables (relative humidity (a), wind speed (b) and precipitations (c)) simulated by the model (full line) and observed at Saclay site (dotted line) from 15 July to 1 August 2000. The comparison of PBL height (d) calculated by the model (full line) and observed by Trappes radiosoundings (crosses) twice a day at 00:00 and 12:00 UTC is also presented. The 24 and 26 July undergo instable, cloudy weather conditions.

that MM5's wind has the same order of magnitude as the observed one. Figure 6 shows the wind speed fluctuations measured aboard the ARAT aircraft together with these simulated by MM5. The general pattern of the wind speed is well reproduced while the high-frequency variability is not. Note that for 31 July, wind speed seems slightly underestimated within the PBL, which may lead to a misplacement of the aerosol plume. Finally, we also compared the wind speed simulated in the first model layer (representative of the mean wind up to $50 \mathrm{~m}$ ) with the corresponding measurements at 10 and $50 \mathrm{~m}$ obtained at Saclay site during the second half of July 2000. The results displayed on Fig. 7b demonstrate the ability of the model to reproduce the temporal variability of the wind speed. Moreover, the comparison indicates that the modeled wind stays in between the observed values, which confirms the absence of systematic biases in simulations.
On 19 July MM5's $R H$ is slightly larger than actual $R H$ in the PBL (Fig. 5). This model bias is clearly visible from the comparison with aircraft measurements (Fig. 6). On 31 July the observed $R H$ values are reproduced fairly well by the model, except at the top of the PBL where an underestimation of $30 \%$ in predicted values is obtained. These differences in $R H$ can have a significant impact on aerosol thermodynamics and chemistry, and thus on the aerosol optical properties at the top of PBL.

Finally, the comparison of observed and simulated potential temperature profiles shows a rather good agreement within the PBL suggesting a correct diagnostic of the simulated PBL height, particularly on 19 July. On 31 July, the comparison reveals a slight underestimation of the observed PBL height also visible on $R H$ profiles. A more systematic comparison (Fig. 7) of the MM5 PBL height is made 
with Trappes Radiosounding measurements during the second half of July 2000. PBL height was determined from the Richardson number and potential temperature profiles. In MM5 PBL height is calculated in a similar fashion as in Troen and Mahrt (1986), based on a critical value (0.5) of the bulk Richardson number in the MRF PBL scheme. There is a generally good agreement between simulated and measured daytime PBL heights, although the synoptic hour for radiosoundings (12:00 UT) often occurs during the sharp ascent of the PBL, leading to potentially large differences in the comparison. The model has more difficulties in simulating the night-time PBL height. Errors in simulated PBL height could generate large discrepancies between observed and modeled concentrations of primary pollutants. Such is the case on 31 July when the model underestimation of PBL height results in erroneous $\mathrm{PM}_{10}$ and $\mathrm{NO}_{\mathrm{y}}$ peaks in the morning (see Sect. 5.1). On the contrary, the model night-time overestimation of the PBL height on 23-24 July and 27-29 July results in too low $\mathrm{PM}_{10}$ and $\mathrm{NO}_{\mathrm{y}}$ concentrations.

On 19 July, the calculated PBL reaches $1700 \mathrm{~m}$ in the afternoon and is in good agreement with observations, while on 31 July the model underestimates the PBL height by about $200 \mathrm{~m}$, with maximal values of $1300 \mathrm{~m}$ in the south of Paris, which is probably the result of discrepancies observed on simulated pollutant concentrations (see Sect. 5).

\section{Analyses and interpretation of comparison results}

The aim of this section is to evaluate the model performances in simulating the observed spatial structure, mass, chemical and optical characteristics of aerosols during selected pollution episodes. The correctness of the simulation of other pollutants (ozone, $\mathrm{NO}_{\mathrm{x}}$ ) is also discussed for comparison, in order to distinguish errors that may arise from erroneous transport or emissions from errors specifically due to aerosol processes.

Several points are discussed: (i) first we examine the ability of the model to reproduce pollutant concentrations near their sources based on the comparison with ground stations, (ii) then, the plume location and its spatial extension is assessed from airborne measurements; (iii) the chemical composition of the Parisian aerosol is also evaluated at the Saclay site in the southwest of Paris; and (iv) finally, the aerosol vertical profiles and their optical properties are studied from airborne lidar data and their characteristics are given for a polluted urban environment.

\subsection{Surface concentrations of Ozone, $\mathrm{NO}_{\mathrm{y}}$ and $\mathrm{PM}_{10}$}

As shown by Fig. 4, the model faithfully reproduces the surface ozone time variations when averaged over urban or rural stations of the AIRPARIF network, except during 1617 and 24-27 July which are characterized by very cloudy conditions. As seen from rural station comparisons, back- ground ozone levels are also correctly simulated by the model. Moreover, the evolution of the primary $\mathrm{NO}_{\mathrm{y}}$ concentrations near the surface is rather well captured during this period, except on 31 July when the model overestimates the observed concentrations by a factor of 2. This discrepancy may be caused by too weak boundary layer mixing at peak traffic hours, but also by too strong emissions. A very specific traffic pattern is expected during the last days of July when large numbers of people start their vacations. According to the recent study of Beaver et al. (2006), holiday emission patterns are characterized by higher emissions spread throughout the day, which can result in higher ozone levels than the weekdays or weekends. These patterns are not accounted for in the current emission inventories, which can result in large uncertainties in the daily emissions distribution during the holidays.

For $\mathrm{PM}_{10}$, important discrepancies between modeled and observed concentrations are found from 17 to 20 and on 31 July during night and morning hours when the model simulates high $\mathrm{PM}_{10}$ peaks and largely overestimates the observed concentrations. This could result from numerous factors discussed in Hodzic et al. (2005), the most likely one being an overestimation of the aerosol emission inventory over Paris (by about 30\%). The fact that $\mathrm{NO}_{\mathrm{y}}$ is well simulated from 17 to 20 July indicates that the model error on $\mathrm{PM}_{10}$ does not result from too weak vertical mixing during this period. On 31 July, characterized by too high $\mathrm{NO}_{\mathrm{y}}$ values, the large overestimation of modeled $\mathrm{PM}_{10}$ concentrations probably results from the combination of dynamical and emission errors.

\subsection{Plume location and characteristics}

We now evaluate the model's ability to transport the daytime pollution plume away from the main emission source area (the city center), using airborne measurements aboard the ARAT aircraft. The spatial structure of the simulated $\mathrm{PM}_{10}$ concentration fields is shown in Fig. 1. On 19 July, the model develops a pollution plume over the south-west of the area, with concentrations close to $35 \mu \mathrm{g} / \mathrm{m}^{3}$ in the afternoon, while on July 31, the $\mathrm{PM}_{10}$ plume is located in the north of Paris and concentrations within the plume are close to $45 \mu \mathrm{g} / \mathrm{m}^{3}$ in the afternoon.

To assess the plume position we only have ozone and NO measurements. $\mathrm{PM}_{10}$ concentrations are not measured aboard the aircraft because of measurement constraints that require long-time exposure of sensors. Figure 8 shows ozone and NO concentrations observed and simulated along the ARAT flight trajectories on 19 and 31 July. On 19 July, the comparison performed for both pollutants along lowaltitude flight legs indicates that the plume position and amplitude are well simulated. On that day the air mass entering the domain is characterized by high ozone concentrations close to $70 \mathrm{ppbv}$ at 11:00 UTC. The observed upwind (background) concentrations of ozone are underestimated by about $5-10 \mathrm{ppbv}$ in model simulations, although 
a)

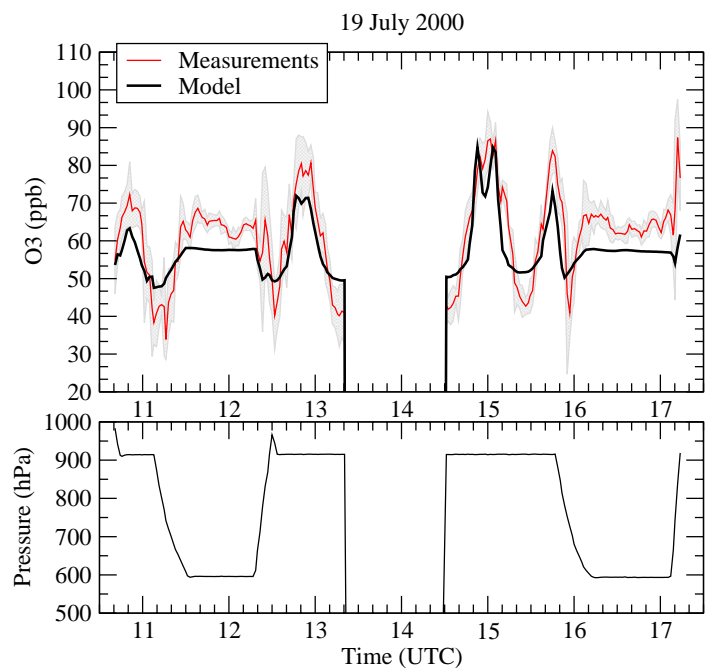

b)

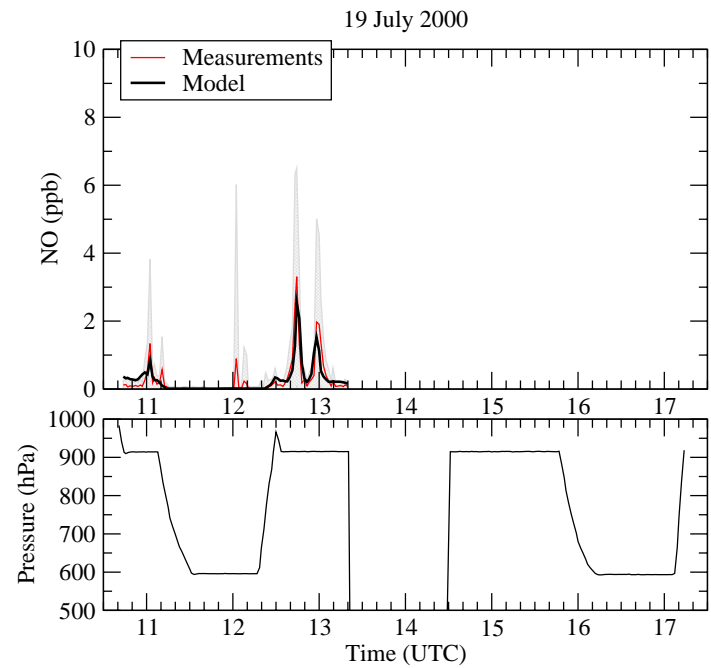

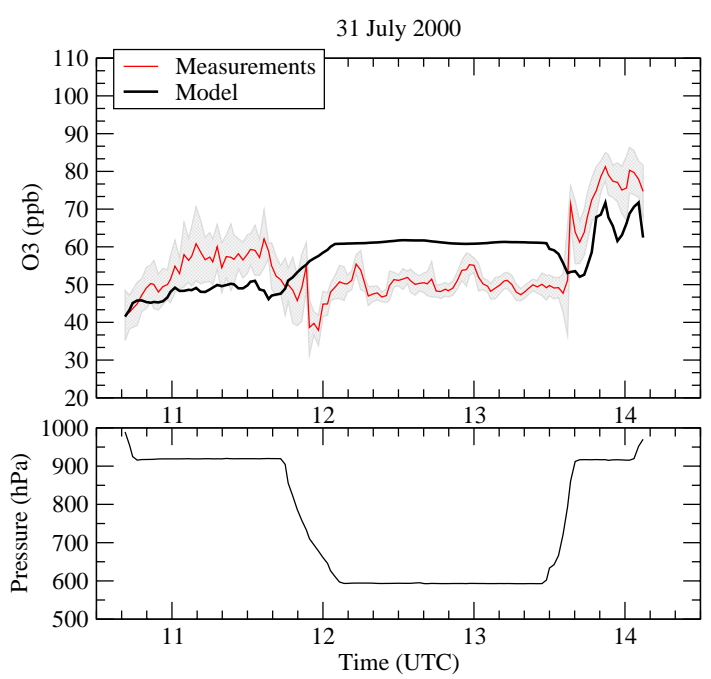

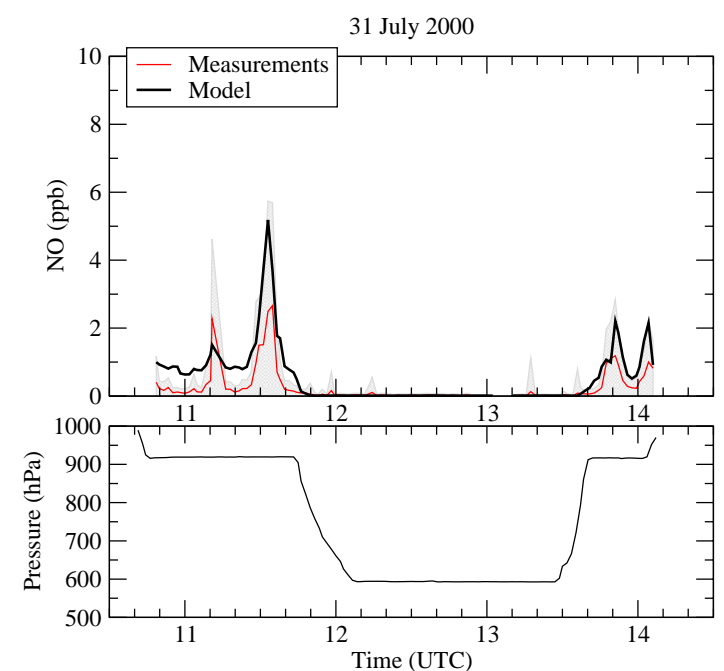

Fig. 8. Time series of $\mathrm{O}_{3}$ (a) and $\mathrm{NO}$ (b) concentrations (ppbv) as observed (red line) during the ARAT flight and simulated by CHIMERE model (black line) on 19 and 31 July 2000.

the simulated concentrations lie within the acceptable observation uncertainty interval. This background underestimation is again found within the plume south-westerly of Paris at 13:00 UTC. A better agreement is obtained in the afternoon (15:00 UTC) during the second part of the flight. The plume characteristics (width and amplitude) are faithfully reproduced.

As shown by backtrajectories (Chazette et al., 2005) issued from the HYSPLIT model, the air mass is of maritime origin on 31 July (Sect. 4) and is characterized by lower ozone background concentrations (50 ppbv). The difference between upwind and downwind concentrations corresponds to the local production of ozone that reaches about $30 \mathrm{ppbv}$ (Fig. 8a). The comparison performed along the flight trajec- tory suggests that ozone concentrations are underestimated by about $10 \mathrm{ppbv}$ in the close suburban area of Paris, however the plume structure is reproduced in the afternoon. A good agreement obtained between model simulations and ground observations in remote rural sites suggests that the underestimation is not caused by too low ozone boundary conditions (Fig. 4). The underestimation of ozone concentrations at urban sites and within the plume is most likely a result of the overestimation of $\mathrm{NO}_{\mathrm{y}}$ concentrations (Fig. 8b), in agreement also with the surface $\mathrm{NO}_{\mathrm{y}}$ overestimation in Paris (Sect. 5.1). This is also consistent with the underestimation of the wind speed and PBL height on this day (see Fig. 5), which make the model dispersion weaker than in reality. 


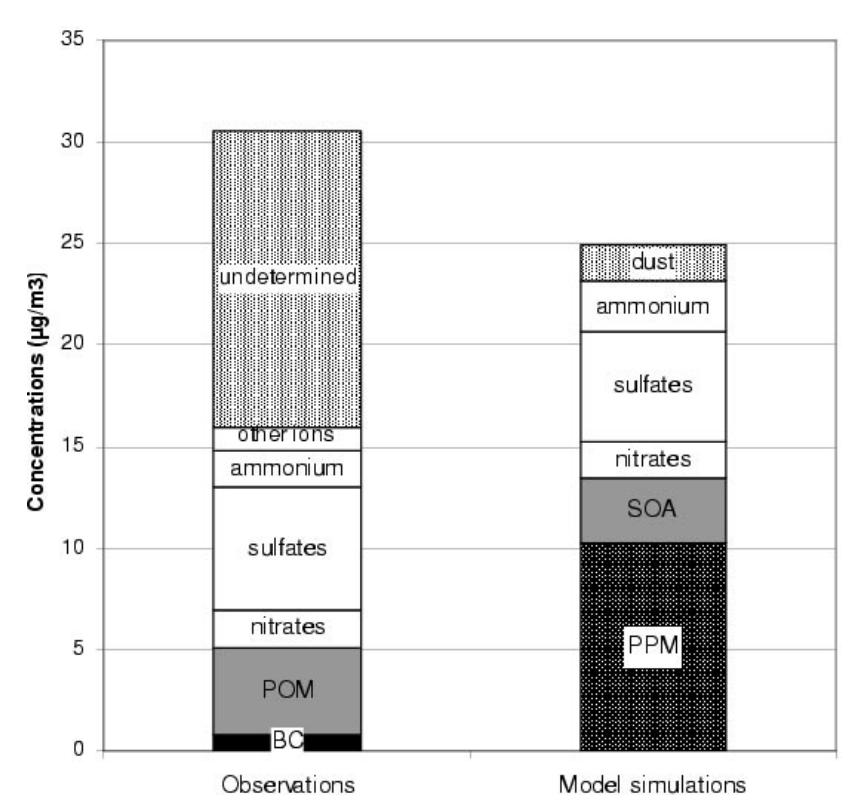

Fig. 9. Average concentration of the main aerosol components in the TPM. Black Carbon (BC), Particulate Organic Matter (POM), Secondary Organic Aerosols (SOA), Primary Particulate Matter (PPM).

In addition, the comparison (not shown here) between the $\mathrm{R} 1$ and the R2 model runs indicates that the model results are not significantly affected by the model vertical resolution during the study period. The simulated meteorological variables and pollutant concentrations vary less than $5 \%$ within and $10 \%$ above the boundary layer.

\subsection{Aerosol chemical composition}

The correct representation of the aerosol chemical composition and their size distribution in aerosol models is essential because these parameters determine aerosol properties and their impact on environment. In this section, the simulated chemical composition of the total particulate matter (TPM) is evaluated using corresponding ground-based measurements obtained from 19 to 26 July 2000 at the Saclay site located in the Southwest of Paris. Since this site is located about $25 \mathrm{~km}$ from the Paris center and about 5-10 km away from the urban area limits, it is representative of a mixed rural and suburban environment. As mentioned in Sect. 2, the chemical composition of observed aerosols has been determined through the analyses of the material collected on the filters. Sampling is performed in two size classes containing, respectively, particles smaller than $2 \mu \mathrm{m}$ and greater than $2 \mu \mathrm{m}$ in diameter, referred to as "fine" and "coarse" aerosol modes, respectively. Uncertainties in the determination of the aerosol constituents are estimated to be within 5-10\% (Jaffrezo et al., 1994) for inorganic species (IS) and within 10-20\% (Brémond et al., 1989) for both total carbon (TC) and organic carbon (OC). The aerosol residual fraction, including dust, is calculated by

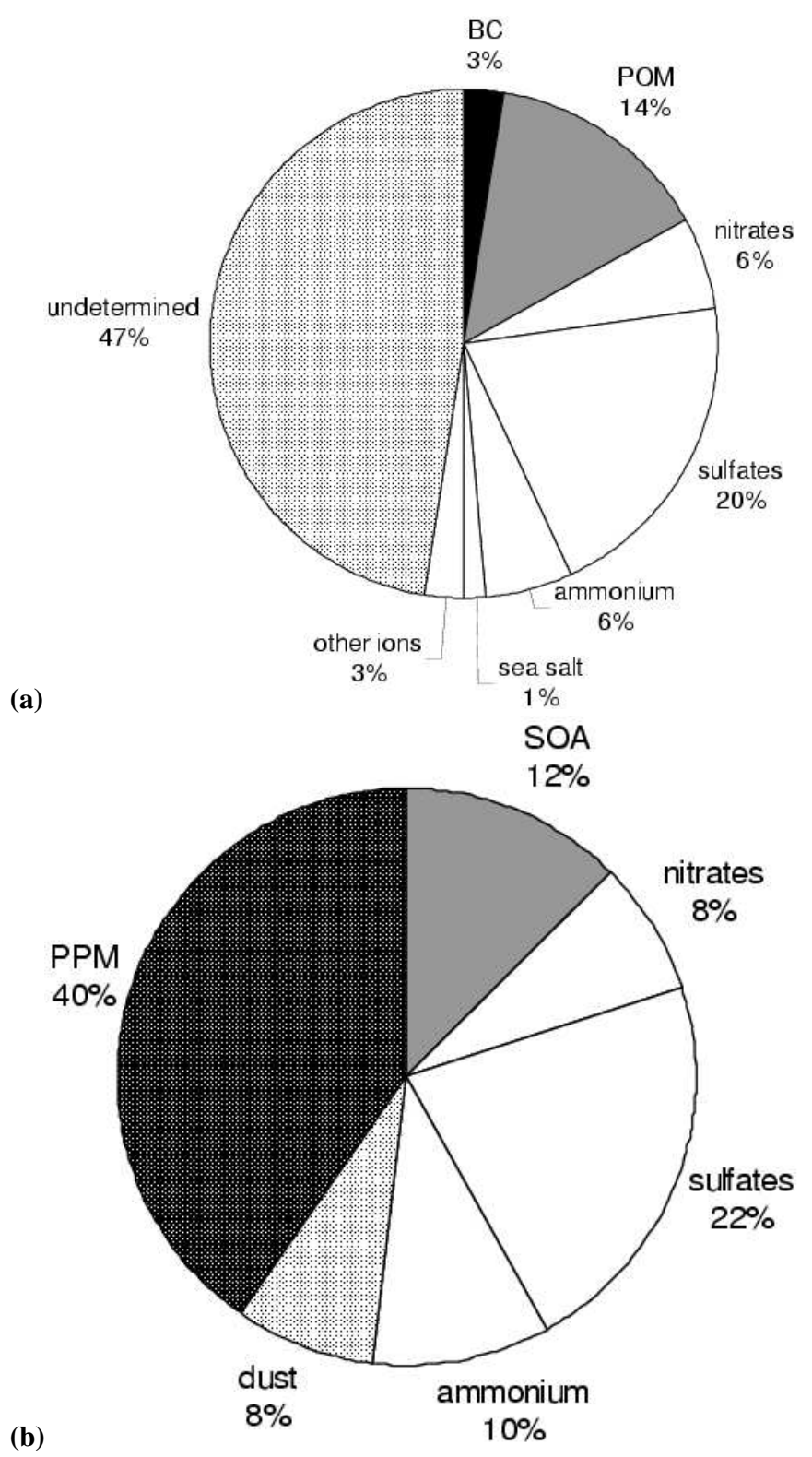

Fig. 10. Fractional contribution of the aerosol components to the total aerosol mass as (a) observed and (b) calculated by CHIMERE model at Saclay site.

the difference: TPM - (BC+1.3 OC+IS). For the comparison, the model concentrations are averaged over the time periods corresponding to measurement samples. Daytime (08:0020:00 UTC) and nighttime (20:00-08:00 UTC) periods are distinguished.

\subsubsection{PM chemical composition}

Figure 9 shows the average mass concentration split of the total aerosol into components measured and simulated over the period. The tops of the bars indicate the total PM 


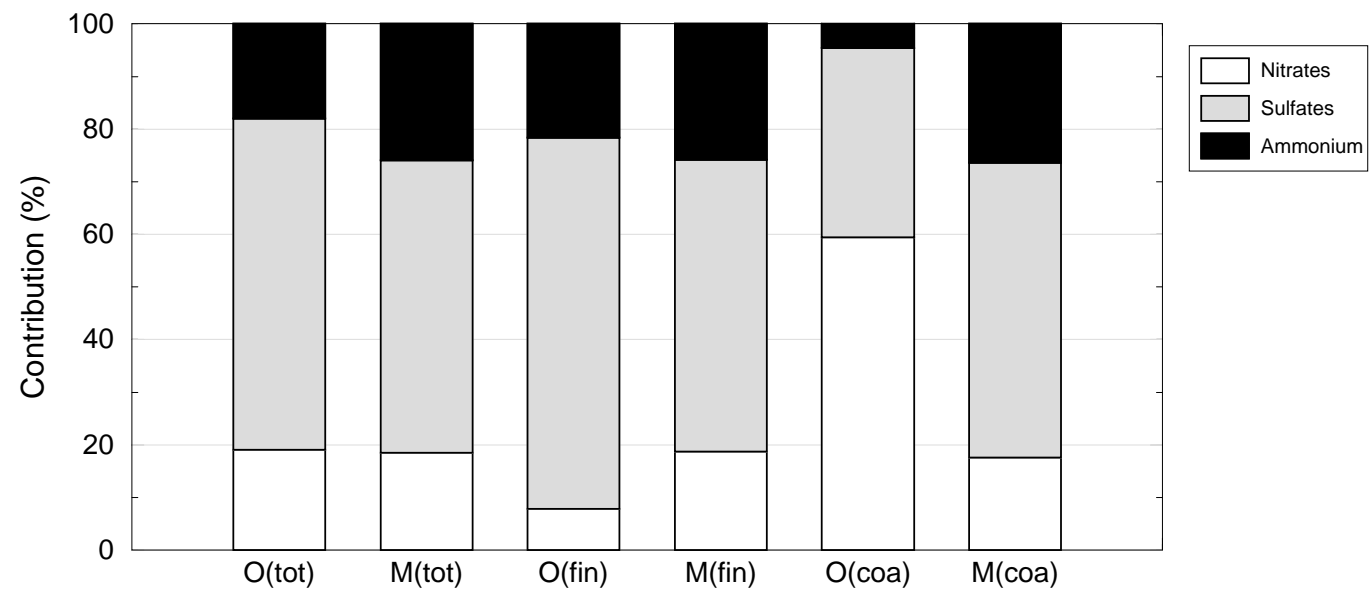

Fig. 11. Relative composition of the inorganic aerosol fraction as observed $(\mathrm{O})$ and modeled $(\mathrm{M})$ for total PM mass (tot), fine (fin) and coarse (coa) aerosol mode.

concentrations. The measured mean concentration reaches $\sim 30 \mu \mathrm{g} / \mathrm{m}^{3}$ during this period, while the model simulated aerosol total mass is close to $25 \mu \mathrm{g} / \mathrm{m}^{3}$. This model underestimation of the PM total mass in summer is consistent with previous studies (van Loon et al., 2004; Hodzic et al., 2004; Vautard et al., 2005). The average percentage contribution of the different chemical components to total dry aerosol mass is given in Fig. 10. Observations indicate that the aerosol is composed of $3 \%\left(\sim 1 \mu \mathrm{g} / \mathrm{m}^{3}\right)$ black carbon, $14 \%\left(\sim 4 \mu \mathrm{g} / \mathrm{m}^{3}\right)$ particulate organic matter (POM) and $36 \%\left(\sim 11 \mu \mathrm{g} / \mathrm{m}^{3}\right)$ inorganic material. The remaining aerosol fraction called "undetermined" mass, represents $47 \%$ of the total aerosol mass and is composed of other chemically non-identified aerosol components that may include mineral dust, re-suspended material, etc. This reflects the importance of uncertainties involved in measurements.

The simulated aerosol is dominated by primary particulate matter (40\%) that accounts for anthropogenic primary emissions. The modeled PPM fraction is not directly comparable with measurements as it contains the black carbon, a significant part of POM and also a part of the "undetermined" aerosol fraction. In the model, the distinction between organic and elementary carbon is not made because the chemical speciation of primary fine and coarse PM emissions is not available in the present inventory. The mineral dust produced from local soil erosion or desert dust transport represents $8 \%$ of the simulated aerosol mass.

The contribution of inorganic aerosols of $40 \%$ $\left(\sim 10 \mu \mathrm{g} / \mathrm{m}^{3}\right)$ to the modeled PM mass is in good agreement with the observations. The simulated inorganic matter includes $22 \%$ sulfate, $10 \%$ ammonium and $8 \%$ nitrate, while the observed inorganic fraction contains $20 \%$ sulfates, $6 \%$ ammonium and $6 \%$ nitrate. The model tends to overestimate the relative contribution of the ammonium and nitrate. Other ions such as sodium, chloride, magnesium, calcium and potassium represent $4 \%$ of the total mass of the Parisian aerosol and are not taken into account in the model.
The fraction of the secondary organic aerosols (SOA) represents $12 \%(3 \mu \mathrm{g} / \mathrm{m} 3)$ of the total aerosol mass in model simulations. It is not directly comparable with measured POM $(14 \%, 5 \mu \mathrm{g} / \mathrm{m} 3)$ because this latter includes both primary and secondary organic aerosols. Although the organic matter accounts for a large fraction of urban and suburban aerosol, the relative importance of primary and secondary aerosol is not clearly identified and is highly variable in space and time (Turpin and Huntzicker, 1995). The estimates of the SOA/POM ratio determined by Lonati et al. (2005) for an urban site during the summer-time episode give values close to $85 \%$ indicating that the secondary fraction could dominate the total organic matter. Therefore, a qualitative comparison suggests that the modeled organic aerosol fraction is underestimated, taking into account the potentially large uncertainties involved in the determination of the POM concentrations by applying a relatively low correction factor of 1.3 (Chazette and Liousse, 2001).

Finally, the average composition of the aerosol inorganic fraction, which contributes to the largest part of the total dry aerosol mass, has been examined separately for both fine and coarse aerosol modes. Figure 11 confirms that the contribution of ammonium and nitrate to total inorganic mass is slightly overestimated in model simulations. Moreover, observations indicate that the composition of the inorganic aerosol fraction is strongly influenced by their size distribution. In measurements, the most abundant inorganic species are sulfate $(70 \%)$ and ammonium $(20 \%)$ in fine aerosol mode and nitrate $(60 \%)$ in coarse mode. This large nitrate fraction in the coarse mode is not reproduced in model simulations as the predicted inorganic aerosol fraction displays similar composition for fine and coarse mode. In order to identify possible reasons for discrepancies between modeled and observed data, aerosol components have been examined for each day from 19 to 26 July in Figs. 12-13. 
a)

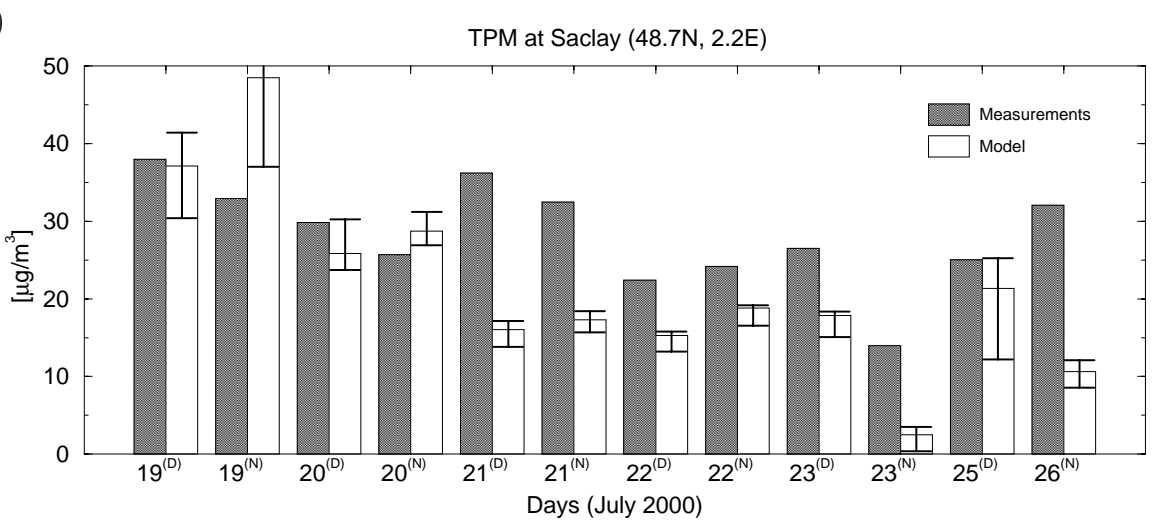

b)

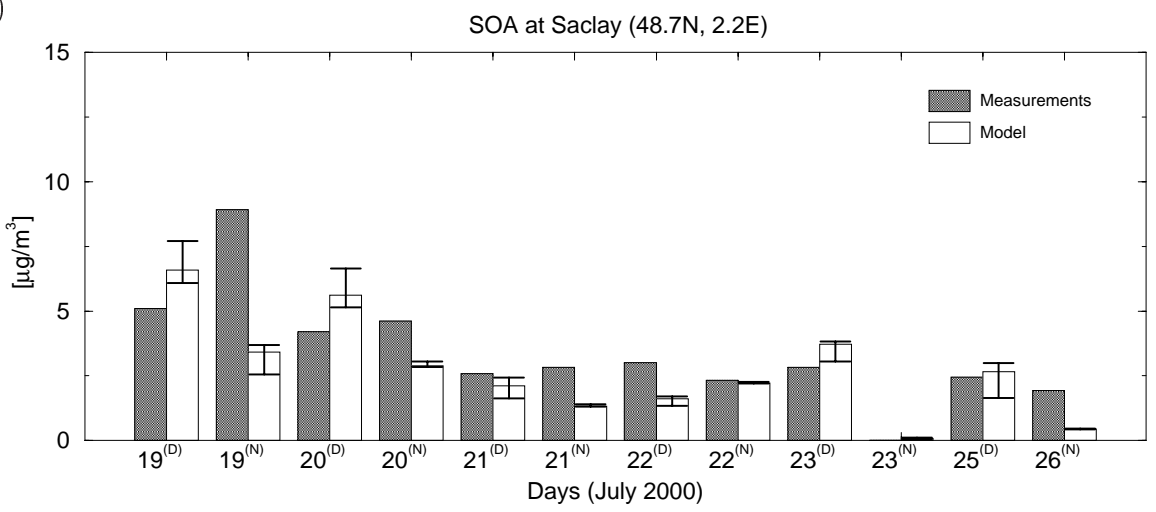

Fig. 12. Daytime ${ }^{(D)}$ and nighttime ${ }^{(N)}$ mean total (a) and secondary organic (b) aerosol concentrations $\left(\mu \mathrm{g} / \mathrm{m}^{3}\right)$ observed (black) and simulated (white) at Saclay site from 19 to 26 July. Bars indicate minimal and maximal values simulated over 9 grid cells surrounding Saclay station. The observed secondary organic fraction has been estimated from the total organic matter according to the $\mathrm{SOA} / \mathrm{POM}=0.85$ ratio reported by Lonati et al. (2005).

\subsubsection{Total aerosol concentration}

In Fig. 12a, the comparison between observed and simulated total particulate mass (TPM) concentrations is presented. Two periods can be distinguished: the pollution episode from 19 to 20 July when the model simulates higher TPM concentrations that are in good agreement with the observed ones; and the period from 21 to 26 July characterized by the model underestimation of TPM mass by about $30-50 \%$ that is consistent with previous modeling results (Hodzic et al., 2005). Higher TPM concentrations simulated at the measurement site downwind of Paris on 19 and 20 July result from the combination of a plume effect and stable atmospheric conditions that limit the dispersion of pollutants (see Sect. 5.1). A rather good agreement obtained with measurements during this episode could result from error compensation between the overestimation of PM emissions in Paris and the general PM underestimation, as seen in the following days. Moreover, the presence of an important horizontal gradient in TPM fields close to the measurement site also contributes to the model night-time overestimation on 19 July as shown by lower values obtained at surrounding grid cells (see uncertainty interval in Fig. 12a). From 21 July on, the increase in the wind speed and PBL height in the morning leads to a higher dispersion of pollutants and results in lower TPM mean concentrations: model simulations display higher negative biases, with a factor of 2 lower values simulated on 21 July. This underestimation is expected in summer during the daytime because the SOA formation is underestimated and the re-suspension processes are not accounted for in the model (Hodzic et al., 2004; Vautard et al., 2005). Finally, as the error compensation between aerosol components could influence the comparison results, a detailed comparison is carried out in the following paragraph.

\subsubsection{Organic aerosol fraction}

The observed total particulate organic matter (POM) includes both primary and secondary organic fractions, while the simulated organic fraction accounts only for the secondary organic aerosols (SOA). Based on results from Lonati et al. (2005), the approximate value of $85 \%$ for the SOA/POM ratio is considered hereafter. This ratio has been applied to observed POM in order to estimate the "observed SOA" as reported in Fig. 12b, even though the measurement site is not urban. This figure displays quite good agreement between 

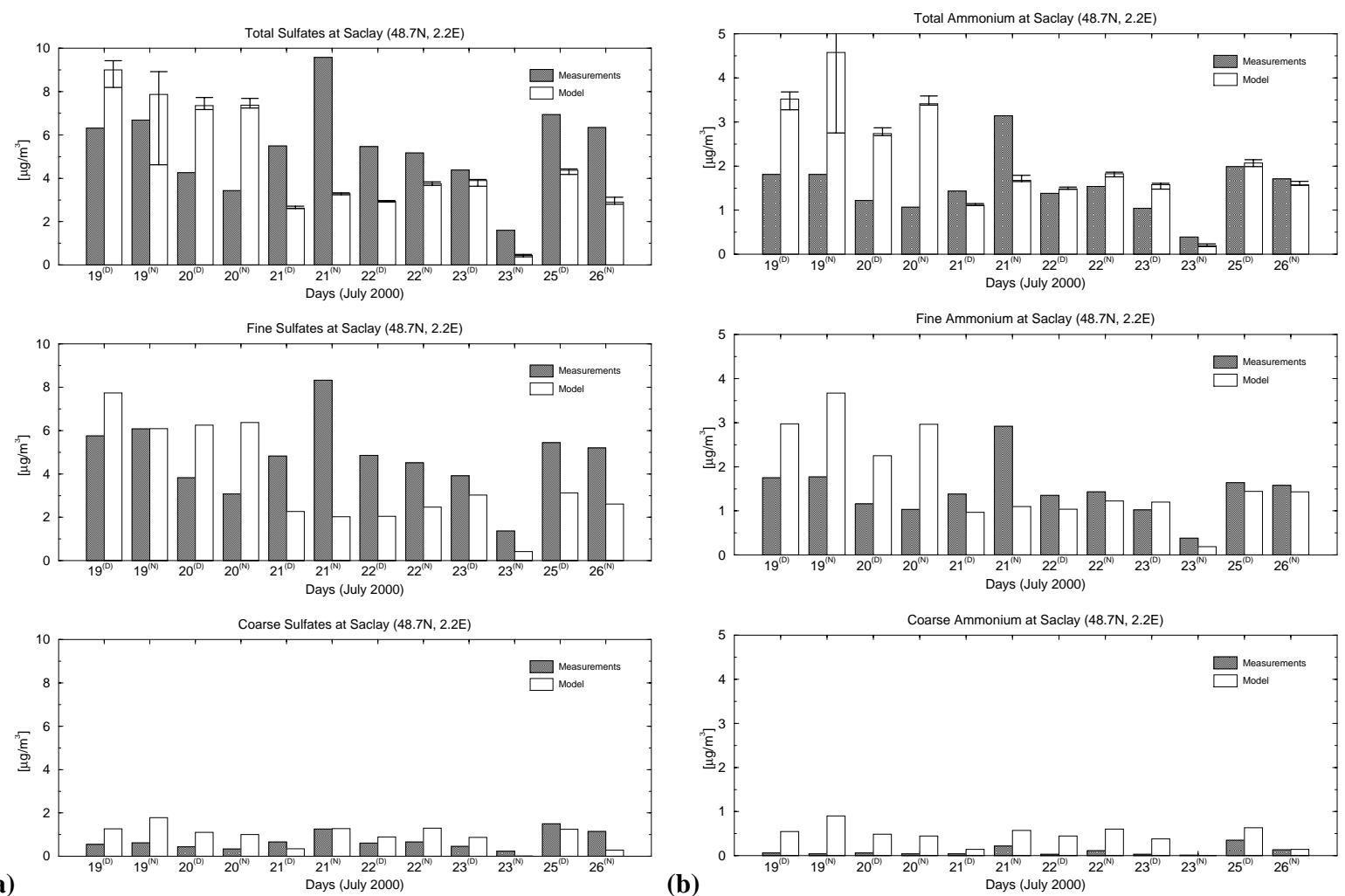

(a)
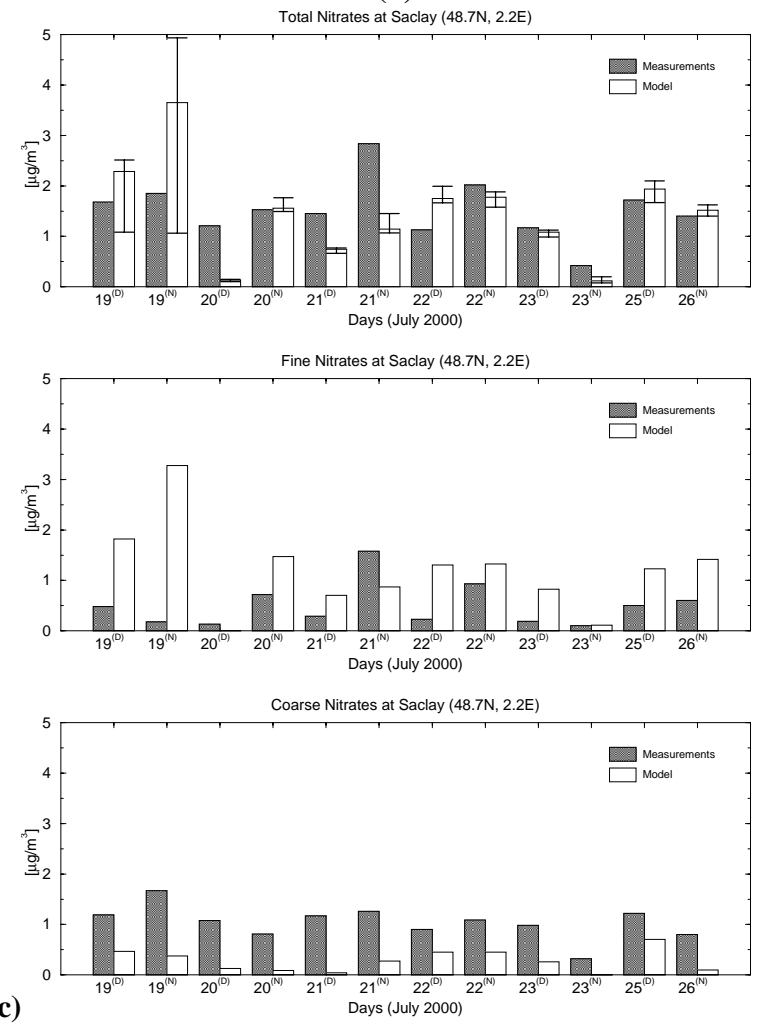

Fig. 13. Daily ${ }^{(D)}$ and nightly ${ }^{(N)}$ mean sulfate (a), ammonium (b) and nitrate (c) concentrations $\left(\mu \mathrm{g} / \mathrm{m}^{3}\right)$ observed (black) and simulated (white) at Saclay site from 19 to 26 July. 
simulated and observed SOA concentrations during the day, and a systematic underestimation during the night. This underestimation is probably larger and occurs during both day and night, as the measured total organic fraction obtained by multiplying organic carbon by 1.3 may be the lower range of its values. Moreover, the day/night time difference in the SOA concentrations is expected because in this model version the temperature-dependence of gas/particle partitioning for organic species is not taken into account. The SOA components are directly transferred to the particulate phase by using a very high partitioning coefficient (no temperature dependence). In doing so, the comparison between observed and simulated SOA concentrations is more relevant during the night than during the day, hence suggesting a net SOA production underestimation.

\subsubsection{Inorganic aerosol fraction}

The comparison between observed and simulated inorganic aerosol fraction for total, fine and coarse mode mass is represented on Fig. 13. Results indicate that the observed sulfate and ammonium components are mainly found in the fine mode, while nitrate is present in both fine and coarse modes. For all components, the model simulates concentrations larger than observed on 19-20 July and lower than observed from 21 to 26 July.

\section{Sulfate and ammonium concentrations}

Sulfate and ammonium concentrations are overestimated by the model from 19 to 20 July and underestimated after (21-26 July). As for the total PM concentrations, the model positive biases obtained at the measurement site downwind of Paris during the pollution episode of 19-20 July originate most likely from too high local emissions of aerosol precursors. Indeed, the model overestimation of sulfate is associated with high $\mathrm{SO}_{2}$ concentrations that are overestimated compared to measurements. Therefore, as the sulfate formation is dominated by gas-phase oxidation of $\mathrm{SO}_{2}$ in summer, the overestimation of $\mathrm{SO}_{2}$ emissions leads to an overprediction of sulfate production on 19-20 July. In the second period, from 21 to 26 July, the model tends to underestimate the observed sulfate concentrations by about $30-60 \%$ during both day and night time. This model negative bias is consistent with results obtained at different European sites (Bessagnet et al., 2004) and reveals that sulfate chemistry is difficult to simulate. The most likely reason is that the homogeneous sulfate production which prevails during dry anticyclonic conditions is too slow in the model. Moreover, an additional reason for the model negative bias could also be the absence of the primary sulfate emissions (Cousin et al., 2005 and references in there). Indeed, to account for a sub-grid formation of sulfates in industrial and car exhaust plumes it should be assumed that a small fraction (2\%, Tan et al., 2003) of total $\mathrm{SO}_{2}$ emissions are directly emitted as sulfate. Finally, it should be noted that the simulated sulfate and ammonium components are mainly found in the fine mode, which is consistent with observations.

\section{Nitrate concentrations}

Total nitrate concentrations are rather correctly reproduced by the model as shown in Fig. 13c. The model tendency to slightly underestimate the observed values could be noticed during the comparison period, except on 19 July due to higher spatial variability in concentrations as indicated on Fig. 13c. The size decomposition shows that the agreement between simulated and observed nitrates actually results from the error compensation between too high model concentrations in the fine mode and too low values (almost vanishing) in the coarse mode. Contrary to the observations, the simulated nitrate is only found in the aerosol fine mode. This size partition is expected since the simulated nitrate is only present as ammonium-nitrate and is mainly formed in the fine mode through the thermodynamical equilibrium with nitric acid. The gas-phase partitioning of nitrate strongly depends on the presence of its gaseous precursors and the atmospheric conditions (Ansari and Pandis, 1999). The absence of fine mode nitrate in measurements could result from evaporative loss of the semi-volatile ammonium nitrate during the sampling and conditioning of filters at temperatures exceeding $20^{\circ} \mathrm{C}$ (Schaap et al., 2004a).

More problematic is the clear and systematic underestimation of coarse-mode nitrate. Differences between observed and simulated concentrations are obviously due to the absence of a coarse nitrate net formation processes in the model. The coarse-mode nitrate has been observed several times during measurement campaigns as reported by Putaud et al. (2004); Cousin et al. (2005) over the Mediterranean area during the ESCOMPTE and MINATROC projects, or at an alpine-site (Henning et al., 2003).

According to previous references, the coarse mode nitrate could be explained as calcium nitrate formed by heterogeneous reaction of calcium carbonate with nitric acid onto mineral dust particles. The investigation of the role of such a process is left for a separate study, which is presented in Hodzic et al. (2006b). This process is thought to be responsible for the general underestimation of the total nitrate mass during summer reported in several model studies (e.g., Schaap et al., 2004b; Bessagnet et al., 2004)

\subsection{Aerosol size distribution and number concentrations}

\subsubsection{Mass size distribution}

We now attempt to evaluate the model ability to reproduce the mass size distribution. Figure 14 shows measured and simulated mass size distributions of ammonium, nitrate and sulfate aerosols during ESQUIF IOPs. Measure- 
ments are performed in Paris close to Notre Dame from 18 (07:00 UTC) to 21 (08:00 UTC) July for the first IOP and from 29 (17:00 UTC) to 01 (15:00 UTC) July for the second one. The measurements are taken at ambient relative humidity, about $50 \%$ during both IOPs.

For both episodes, the observed sulfate mass distribution is bimodal with mean diameters close to $0.3 \mu \mathrm{m}$ in fine and 2$3 \mu \mathrm{m}$ in coarse mode, while the ammonium and nitrate mass distributions are unimodal with respective fine mode diameter of $0.3 \mu \mathrm{m}$ and coarse mode diameter around $2-3 \mu \mathrm{m}$.

The model is unable to represent the size variability and multimodality of aerosol components. Simulated mass distributions are wide and unimodal, with mean diameters in the range $0.5-0.9 \mu \mathrm{m}$ for all components. Many factors can be responsible for this deficiency. Numerical diffusion in transsectional transport (absorption) inevitably acts to smooth gradients in the mass distribution.

Finally, other ions such as calcium and sodium are also observed in the coarse mode with respective mean diameters in the ranges $3-5 \mu \mathrm{m}$ and $2-3 \mu \mathrm{m}$. The presence of a significant amount of calcium confirms the possible heterogeneous formation of coarse nitrate as calcium nitrate previously discussed. The results reported in our recent study (Hodzic et al., 2006b) show that the introduction of the heterogeneous formation of coarse nitrate onto dust particles in the model increases considerably coarse nitrate concentrations of $0.5-2 \mu \mathrm{g} \mathrm{m}^{-3}$ during the ESQUIF study period (see Fig. 6 in Hodzic et al., 2006b) and leads to a bimodal aerosol distribution.

\subsubsection{Aerosol number concentration}

We performed the comparison of measured and simulated particle number concentrations along flight trajectories for both episodes. Figure 15 presents the results of the comparison obtained respectively for the total aerosol size distribution (particles with diameters in range 0.01-3 $\mu \mathrm{m}$ ) and the accumulation mode (particles with diameter in the range $0.1-1.0 \mu \mathrm{m}$ ). The greatest number of aerosols is found in the fine mode, especially in model simulations. On both days, the comparison reveals that the total aerosol number concentrations are generally overestimated by the model within the plume with peak values that could reach 30000 particles $/ \mathrm{cm}^{3}$. The transition between lower background and higher plume number concentrations is clearly identified in the model. In the accumulation mode, higher aerosol number concentrations are observed on 19 than on 31 July due to aged air mass. In this mode, the spatio-temporal variability is particularly well captured, while the number concentrations are underestimated by about $30-50 \%$. Several factors could be responsible for such model behaviour. First, the model number concentrations are sensitive to the size distribution of primary particulate emissions (Kahnert et al., 2003). In our model the $\mathrm{PM}_{2.5}$ mass emissions are log-normal distributed with a mean diameter of $0.1 \mu \mathrm{m}$ and a standard deviation of
$1.6 \mu \mathrm{m}$. The choice of distribution parameters (diameter and standard deviation) influences the number concentrations in the accumulation mode, but is not sufficient to explain the obtained underestimation. Moreover, the lack of secondary organic aerosols, or the absence of re-suspension of soil material could also contribute to this underestimation. However, the most reliable explanation consists in the numerical artefact that occurs when calculating the aerosol number concentrations. Indeed, we should keep in mind that the model was designed for the aerosol mass calculation. Therefore, the small errors on the aerosol mass concentrations that can occur in the fine mode could be considerably amplified when considering the aerosol number concentrations.

\subsection{Aerosol optical properties}

The Paris plume vertical structure is also studied from airborne lidar measurements during the 31 July pollution episode. The lidar-derived aerosol optical thickness (AOT) and backscattering vertical profiles are compared with corresponding model-simulated optical parameters along flight legs. As described in Chazette et al. (2005), the lidarderived AOT is calculated from lidar backscattering profiles at $532 \mathrm{~nm}$ using lidar inversion method and assuming constant backscattering-to-extinction ratio $\left(0.014 \mathrm{sr}^{-1}\right)$, refractive index ( $\mathrm{m}=1.5-0.016 \mathrm{i})$ and Angstrom exponent (2.1). According to the results reported in Chazette et al. (2005), the mean relative error for the extinction coefficient is less than $10 \%$ when the inversion of lidar profiles is constrained using a Sun photometer and when the relative humidity stays lower than $75 \%$, as is the case here. The model-derived aerosol optical properties are estimated from model outputs following the method described in Hodzic et al. (2004). Given the simulated aerosol size distribution and mass concentrations, the aerosol optical thickness is calculated using the Mie-theory extinction coefficients depending on the aerosol refractive indexes and their hygroscopic properties. For the comparison of AOT levels, the refractive index is fixed to $m=1.5-0.016 i$ to be coherent with observations, as in Chazette et al. (2005), while for the comparison of the aerosol vertical distribution the refractive index depends on the aerosol composition and relative humidity (Hänel, 1976). The variability in the calculated refractive index using Mie theory and accounting for aerosol composition and relative humidity was calculated to be $m=(1.49 \pm 0.009)-i(0.06 \pm 0.01)$ at $532 \mathrm{~nm}$ for $31 \mathrm{July}$ over Paris region, which is in good agreement with the observations.

Figure 16 shows a south-north flight cross section, chosen to discuss the position of the aerosol plume on 31 July. We notice that the aerosol plume has a significant signature in the AOT fields at $532 \mathrm{~nm}$, with a maximum value close to 0.25 in the plume center. The observed AOT increases from lower values in the south of Paris $(0.15)$ to higher ones in the north (0.25). This additional aerosol load observed in the northern part of the domain corresponds to the aerosol local 

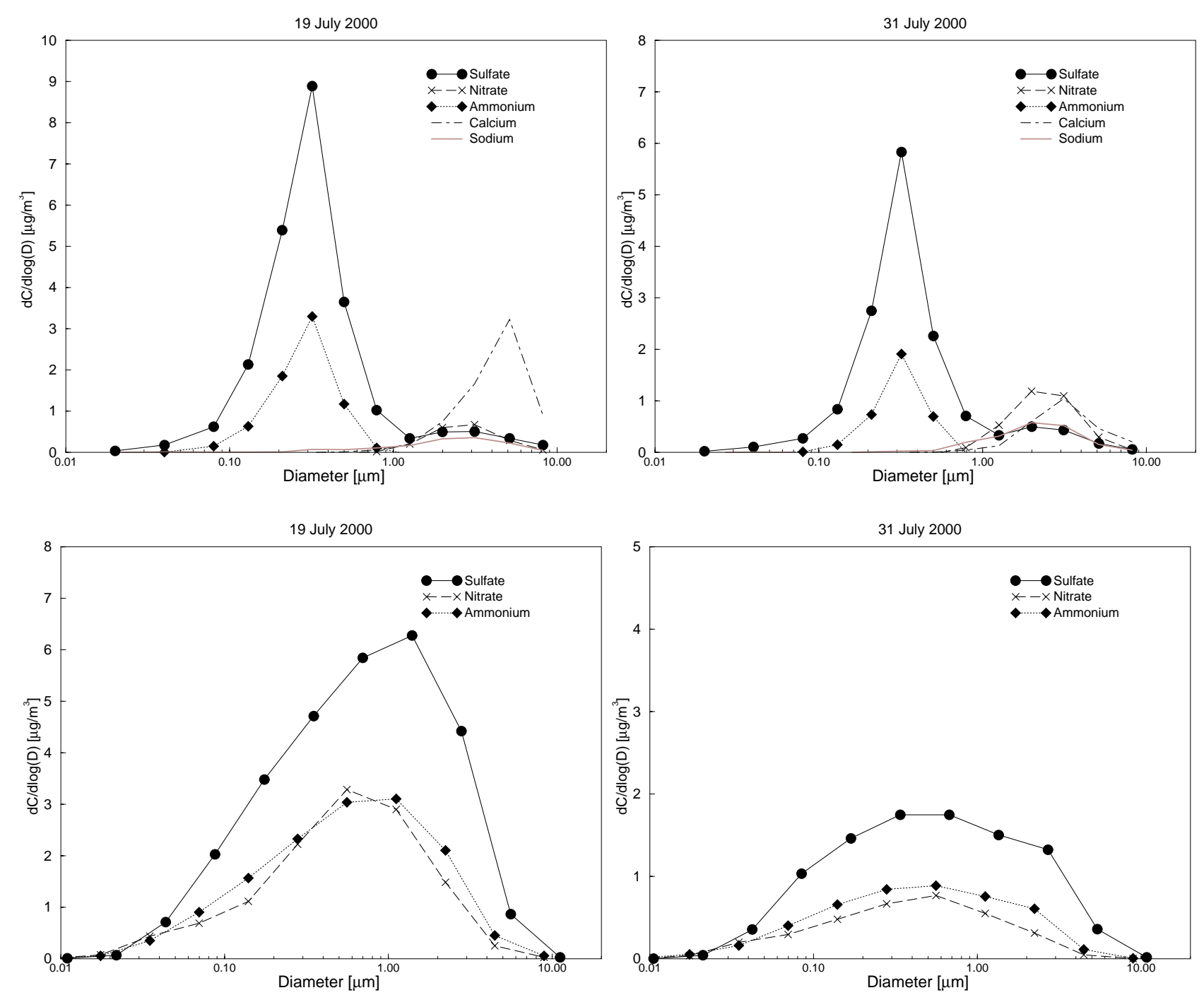

Fig. 14. Mass size distribution of main inorganic components measured and simulated during ESQUIF IOPs.

production of the Paris city area. A more accurate comparison along the flight cross section is presented on Fig. 17. Compared to lidar retrievals, the model correctly reproduces the increase of AOT values and its variation with latitude. However, it generally simulates lower AOTs along the flight leg: close to 0.1 upwind and 0.2 downwind of Paris (Fig. 18). In the south of Paris, model simulated AOT values (0.1) present a better agreement with Sun-photometer data (0.11) obtained at Palaiseau and Creteil (Chazette et al., 2005). Differences with lidar-derived data could be explained by larger uncertainties in the retrieval of the small AOT levels. Moreover, the higher AOT values (0.15-0.2) observed $15 \mathrm{~km}$ upwind of urban Paris over the Orly airport are also underestimated by the model. This model deficiency could be caused by the lack of specific holiday traffic patterns in the model emissions already mentioned in Sect. 5.1.
In the north of Paris, the comparison is more difficult as the plane leg crosses the edge of the simulated AOT plume characterized by an important horizontal gradient. The model under-prediction could result from a too low production of aerosols in the accumulation mode aerosols (optically most efficient), but also from errors in the plume location. A better agreement would be obtained if the model plume was shifted $5-10 \mathrm{~km}$ eastwards. Moreover, the maximum AOT values are observed $30 \mathrm{~km}$ north of Paris suggesting that the simulated plume is located too close to Paris. This could result from the underestimation of the wind speed as previously discussed.

Lidar vertical profiles collected during the flight also provide valuable information on the vertical distribution of the aerosol load, the plume extension and the PBL height. Figure 18 shows the spatial evolution of observed and simulated backscattering ratios (BSR) along the flight leg. The lidar backscatter ratio (unitless) is proportional to the aerosol load 
a)
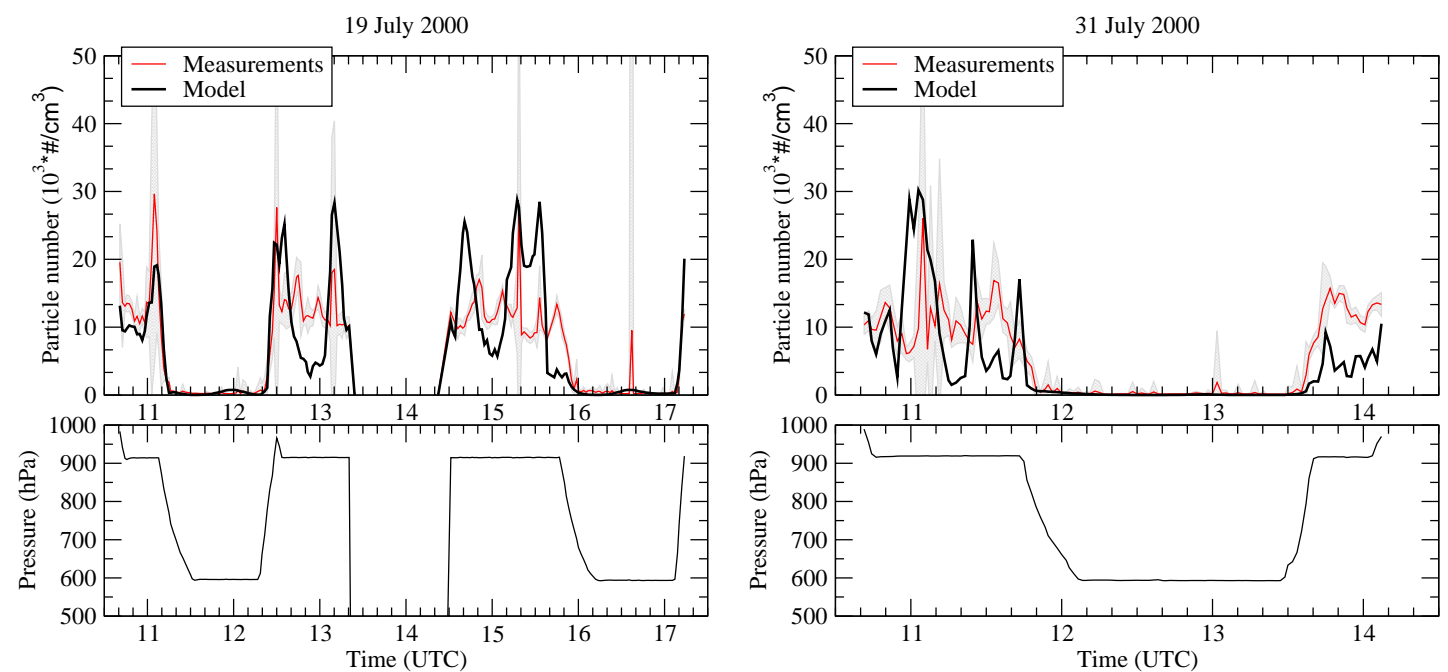

b)
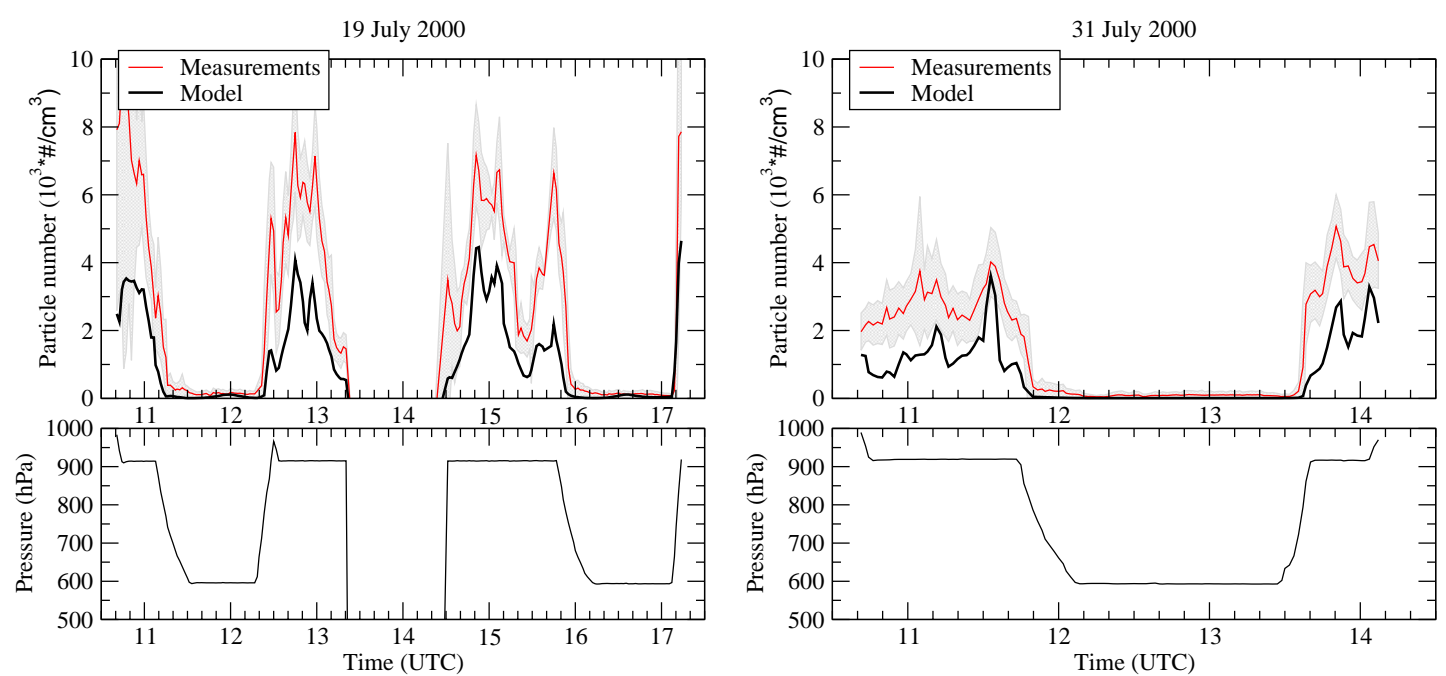

Fig. 15. Aerosol total (a) and accumulation mode (b) number concentrations along ARAT flight trajectories as observed and simulated by CHIMERE model on 19 and 31 July 2000. The accumulation mode contains particles with diameters in ranges 0.1 to $1.2 \mu \mathrm{m}$.

and is computed at each model level according to the relation:

$\operatorname{BSR}(z)=1+\frac{\beta_{a}(z)}{\beta_{m}(z)}$

where $\beta_{a}$ and $\beta_{m}$ are respectively the volume backscattering coefficients for the atmospheric aerosols and molecules at altitude $z$, both in units of $\left(\mathrm{m}^{-1} \mathrm{sr}^{-1}\right)$. These parameters are computed as in Hodzic et al. (2004).

The lidar vertical profiles (Fig. 18) show a progressive increase in the BSR values from upwind to downwind of Paris. In both observations and model simulations, the plume is clearly seen north of $48.6^{\circ} \mathrm{N}$. We also notice that the lidar BSR increases significantly from the ground to the top of PBL where it reaches its maximum value. In the Rayleigh region, above the PBL, the BSR is close to 1 . Thus, the transition between PBL and free troposphere could be clearly identified. The comparison indicates higher values in the observed lidar BSR than in the simulated ones at the top of the PBL. This is readily seen on Fig. 19. The difference of amplitude between the observed and simulated BSR signal within the plume at the top of the PBL is reduced if the modeled plume is shifted $5-10 \mathrm{~km}$ eastwards as demonstrated on Fig. 19b. On the other hand, the increase of the observed BSR layer is associated with an increase of the relative humidity from $55 \%$ at the surface to $80 \%$ at the top of the PBL (Fig. 5) and could be explained by the aerosol growth caused by the uptake of water. This provides a strong indication that the observed aerosol is hydrophilic both in the clean air mass 


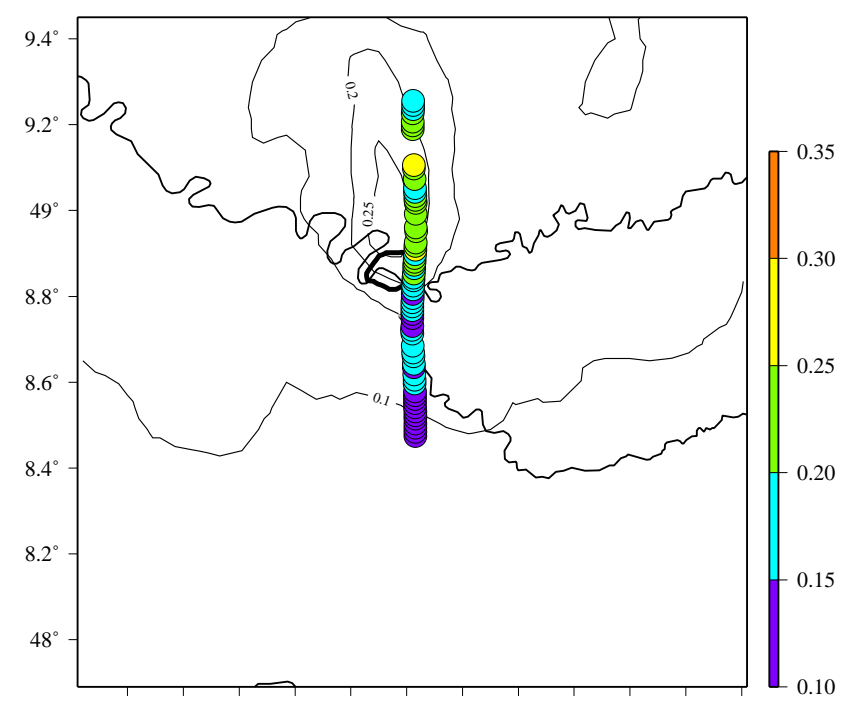

Fig. 16. CHIMERE model simulated aerosol optical thickness $(532 \mathrm{~nm})$ on 31 July over Paris area. The corresponding lidarderived AOTs are superposed along south-north flight leg.

(upwind) and in the plume (downwind). In the calculation of the aerosol backscattering ratio from simulations, the effects of the relative humidity onto aerosol optical properties have been taken into account in the model through Hänel's relation (Hänel, 1976). Therefore, the model underestimation of relative humidity of about 20\% at the top of the PBL (Fig. 5) during this episode could also contribute to the underestimation of the simulated BSR and explains the difference of profile shapes. However, it is difficult to quantify the impact of this possible error on simulated BSR profiles as the aerosol growth is not linear to the increase of relative humidity (Seinfeld and Pandis, 1998).

\section{Summary and discussion}

This article describes the results of an exhaustive aerosol model validation performed over Paris in the framework of the ESQUIF field campaign and based on ground and airborne measurements of aerosol chemical and optical properties. It comes in complement to a paper by Chazette et al. (2005) which presented the optical characterization of the observed aerosol over Paris during the campaign. In the present study, the performance of the CHIMERE model in simulating meteorological variables, gas-phase and aerosol concentrations, as well as the aerosol composition and optical properties, are evaluated with measurements taken during the second part of July 2000. Particular attention is paid to pollution episodes of 19 and 31 July for which airborne data were available.

To assess the model skill, several aspects of the aerosol modeling are discussed: the ability of the model to reproduce the transport and the spatial distribution of pollutants during summertime pollution episodes, the vertical distribution of particles within the boundary layer, and finally the aerosol composition and size-distribution over the Paris region.

The comparison reveals an overall agreement between measured and simulated gas-species and aerosol components during the study period in summer 2000, with the following specific findings:

(i) There are no systematical biases in simulated meteorological variables that govern pollutant dispersion and transport such as wind speed and boundary layer height, although a slightly underestimated wind speed during the IOP of 31 July has been noticed. The simulated plume location and geometry are in good agreement with observations, especially for $\mathrm{NO}$ and ozone.

(ii) The comparison of observed and simulated lidar vertical profiles along flight trajectories on 31 July confirms that the horizontal and vertical aerosol distributions are correctly reproduced in model simulations, although the aerosol load at the top of the boundary layer is underestimated. This discrepancy could be to the result of both a slight misplacement of the plume $5-10 \mathrm{~km}$ westwards and the underestimation of the relative humidity at the top of the PBL slowing the growth of aerosols by the water uptake.

(iii) Ground measurements performed at the Saclay site southwesterly of Paris from 19 to 26 July allowed evaluating the model-simulated aerosol mass and its composition. Although the total aerosol mass is underestimated by about $20 \%$, the aerosol composition is reproduced, especially for inorganic components. The aerosol composition is dominated by primary particulate matter that accounts for anthropogenic and biogenic primary particles $(40 \%)$ and inorganic aerosol fraction including nitrate, sulfate and ammonium $(40 \%)$. The secondary organic aerosols represent $12 \%$ of the total aerosol mass, while the mineral dust accounts for $8 \%$. Detailed evaluation of all aerosol components remains difficult because only inorganic aerosol fraction is clearly identified in measurements. For organic aerosols there are large uncertainties in correction factors applied to measurements in order to account for elements other than carbon. The rough comparison of observed and simulated secondary organic fraction during the campaign confirms the model tendency to underestimate the secondary organic aerosols as found in previous studies, and highlights the necessity of a more accurate modeling of their formation processes. Moreover, the absence of the carbon speciation (into elementary and organic carbon) for primary particulate emissions used in the model does not allow the evaluation of the carbon fraction included in the PPM. 


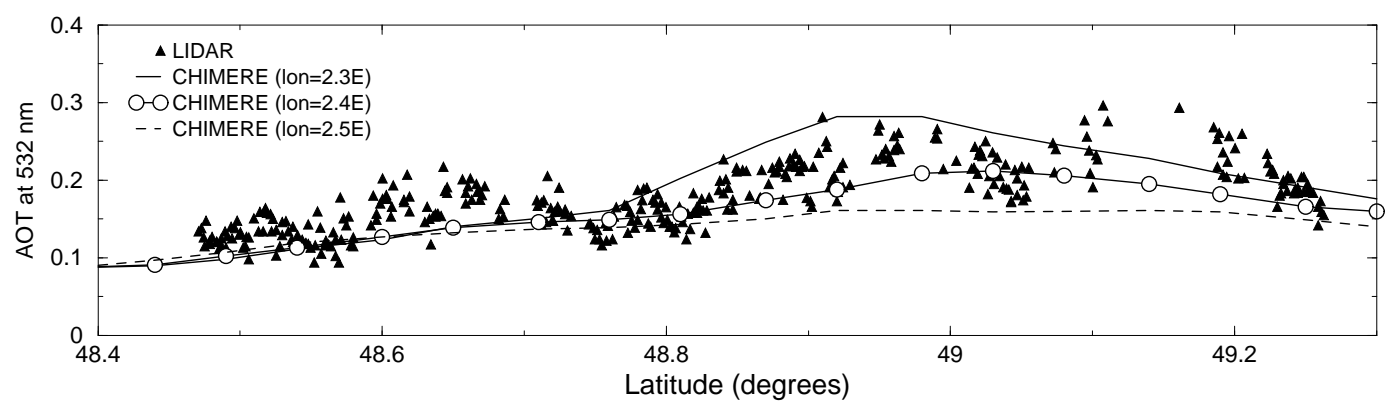

Fig. 17. Lidar-derived and model simulated aerosol optical thickness at $532 \mathrm{~nm}$ along south-north flight leg on $31 \mathrm{July}$.

(a)
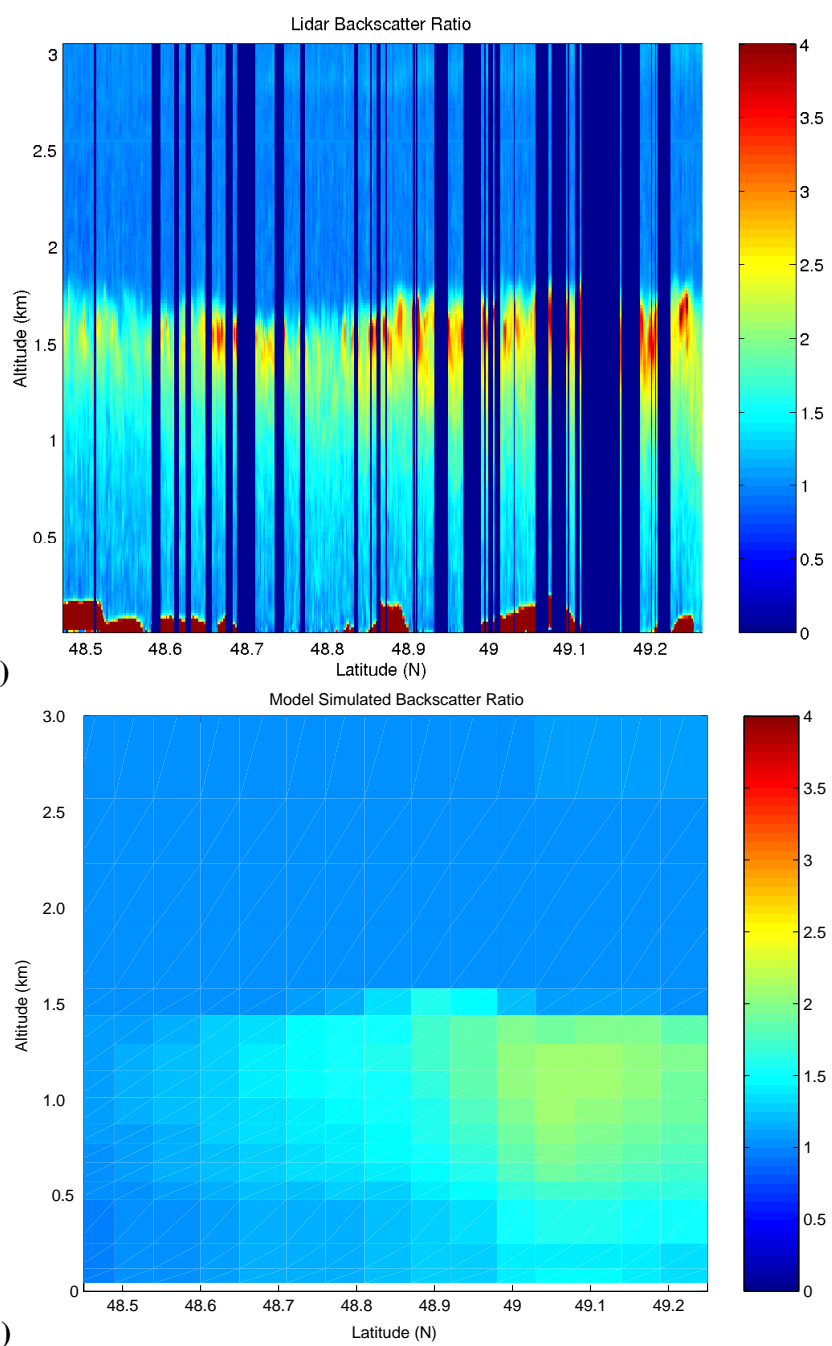

Fig. 18. Vertical profiles of the aerosol backscattering ratio derived from airborne lidar measurements (a) performed along south-north flight leg and simulated by CHIMERE model (b) on 31 July.

(iv) The model reproduces the total levels of nitrate and ammonium and slightly underestimates sulfate concentra-
LIDAR: aerosol backscattering ratio
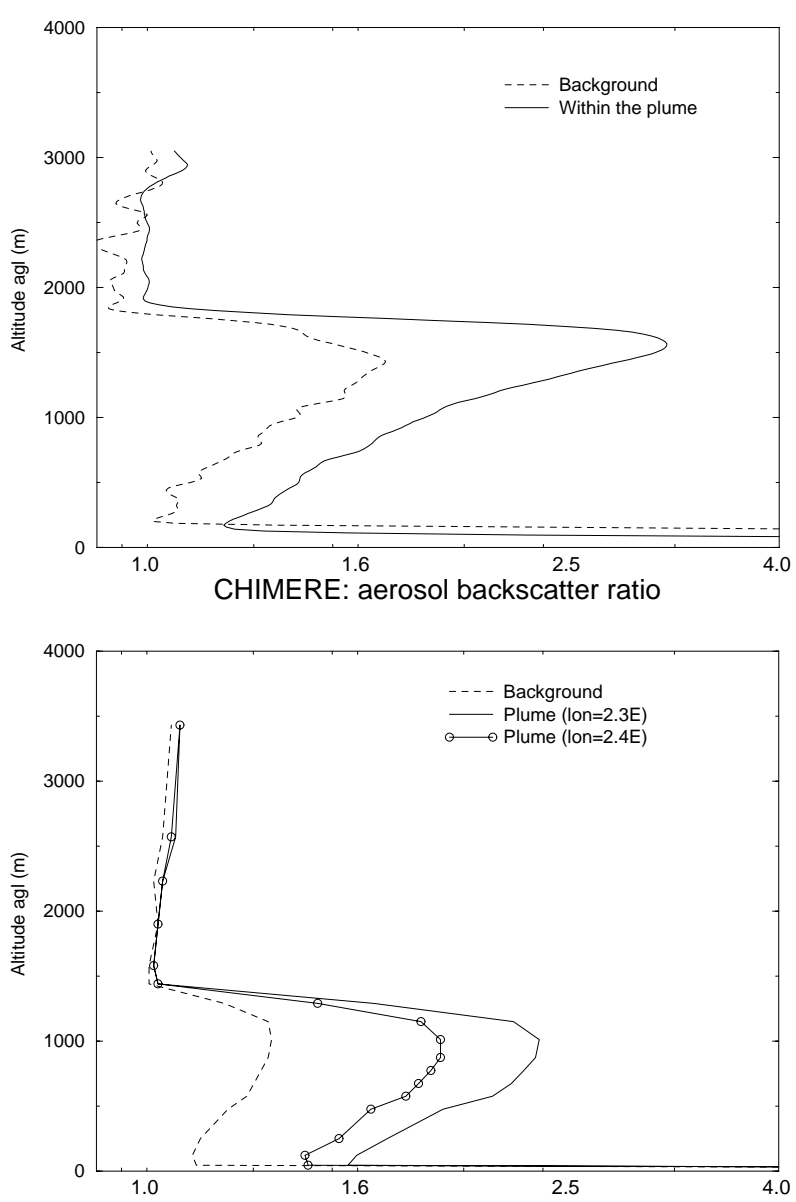

Fig. 19. Vertical profiles of the aerosol backscattering ratio calculated from lidar measurements (south-north flight leg) and model simulations on 31 July.

tions at the end of the study period. The relative agreement in total nitrate concentrations actually results from the error compensation between too high fine-mode and too low coarse-mode nitrates in the model. We argue that the large discrepancies obtained in the fine mode 
could be due to the evaporation of the semi-volatile ammonium-nitrate during the daytime sampling of nitrate, while the systematic model underestimation of coarse-mode nitrate is due to additional formation pathways for nitrate. The implementation of the heterogeneous formation of coarse nitrate onto mineral dust particles in the CHIMERE model is expected to significantly improve the agreement between simulated and observed coarse-mode nitrate concentrations.

(v) The representation of the aerosol mass distribution and its number concentrations in the model is not satisfactory. For inorganic species the simulated mass distribution is characterized by a unique mode with mean diameters in the range $0.5-0.9 \mu \mathrm{m}$, while the observed one is bi-modal (accumulation and coarse modes). The lack of coarse mode particles (nitrate, sea salts, etc.) in the model is not surprising as their formation is not accounted for in this version of the model.

Above all, this work highlights the necessity for further improvements in both aerosol measurements and modeling. As far as modeling is concerned, a very limiting factor for polluted areas is the accurate description of the aerosol composition at the source level. Next, there is a clear improvement needed to achieve modeling of coarse particles and in secondary organics. The accurate simulation of the aerosol mass distributions is also definitely a challenge for future research in modeling. For measurements, as in other aerosol measurement field campaigns, a large fraction of the total mass remains unspeciated, which is a strong limiting factor for model validation.

Acknowledgements. We are grateful to AIRPARIF French air quality association for providing ground station data for Paris region used in this study. This research has been financially supported by ADEME and AIRPARIF. The experimental part of this work was supported by the French "Programme National de Chimie Atmosphérique" from the Institut National des Sciences de l'Univers (INSU), the PRIMEQUAL-PREDIT program of the French Ministry of Ecology and the Commissariat à l'Energie Atomique. The authors thank H. Cachier (CNRS) and S. Alfaro (CNRS) for their help to the chemical analysis of filters. We are also grateful to E. Gilleland (NCAR) for his technical support.

Edited by: G. Feingold

\section{References}

Anderson, T. L., Charlson, R. J., Schwartz, S. E., Knutti, R., Boucher, O., Rodhe, H., and Heintzenberg, J.: Climate forcing by aerosols - a hazy picture, Science, 300, 1103-1104, 2003.

Ansari, A. S. and Pandis, S. N.: An analysis of four models predicting the partitioning of semivolatile inorganic aerosol components, Aerosol Sci. Technol., 31, 129-153, 1999.

Beaver, S., Palazoglu, A., and Tanrikulu, S.: Cluster analysis of meteorological states to understand the weekend-weekday ozone response in the San Francisco, CA Bay Area, 14th Joint Conference on the Applications of Air Pollution Meteorology with the Air and Waste Management Assoc., 2006.

Baertsch-Ritter, N., Prevot, A. S. H., Dommen, J., AndreaniAksoyoglu, S., and Keller, J.: Model study with UAM-V in the Milan area (I) during PIPAPO: simulations with changed emissions compared to ground and airborne measurements, Atmos. Environ., 37(29), 4133-4147, 2003.

Beekmann, M. and Derognat, C.: Monte Carlo uncertainty analysis of a regional-scale transport chemistry model constrained by measurements from the Atmospheric Pollution Over the Paris Area (ESQUIF) campaign., J. Geophys. Res., 108(D17), 8559, 2003.

Bessagnet, B., Hodzic, A., Vautard, R., Beekmann, M., Cheinet, S., Honore, C., Liousse, C., and Rouil, L.: Aerosol modeling with CHIMERE - preliminary evaluation at the continental scale, Atmos. Environ., 38(18), 2803-2817, 2004.

Brémond, M. P., Cachier, H., and Buat-Ménard, P.: Particulate carbon in the Paris region atmosphere, Env. Techn. Lett., 10, 339346, 1989.

Chazette, P. and Liousse, C.: A case study of optical and chemical apportionment for urban aerosols in Thessaloniki, Atmos., Environ., 35, 2497-2506, 2001.

Chazette P., Randriamiarisoa, H., Sanak, J., Couvert, P., and Flamant, C.: Optical properties of urban aerosol from airborne and ground-based in situ measurements performed during the Etude et Simulation de la Qualite de l'air en Ile de France (ESQUIF) program, J. Geophys. Res., 110, D02206, doi:10.1029/2004JD004810, 2005.

Collins, W. D., Rasch, P. J., Eaton, B. E., Khattatov, B. V., Lamarque, J. F., and Zender, C. S.: Simulating aerosols using a chemical transport model with assimilation of satellite aerosol retrievals: Methodology for INDOEX, J. Geophys. Res., 106(D7), 7313-7336, 2001

Cousin, F., Liousse, C., Cachier, H., Bessagnet, B., Guillaume, B., and Rosset, R.: Aerosol modelling and validation during ESCOMPTE 2001, Atmos. Environ., 39(8), 1539-1550, 2005.

Derognat, C., Beekmann, M., Baeumle, M., Martin, D., and Schmidt, H.: Effect of biogenic volatile organic compound emissions on tropospheric chemistry during the Atmospheric Pollution Over the Paris Area (ESQUIF) campaign in the Ile-de-France region, J. Geophys. Res., 108 (D17), 8560, doi:10.1029/2001JD001421, 2003.

Dudhia, J.: A nonhydrostatic version of the Penn State/NCAR mesoscale model: Validation tests and simulation of an Atlantic cyclone and clod front, Mon. Wea. Rev., 121, 1493-1513, 1993.

Dye, J. E. and Baumgardner, D.: Evaluation of the forward scattering spectrometer probe: I. Electronic and optical studies, J. Atmos. Ocean. Tech., 1, 329-344, 1984.

Ginoux, P., Chin, M., Tegen, I., Prospero, J. M., Holben, B., Dubovik, O., and Lin, S.-J.: Sources and distributions of dust aerosols simulated with the GOCART model, J. Geophys. Res., 106, 20 255-20273, 2001.

Guelle, W., Balkanski, Y. J., Dibb, J. E., Schulz, M., and Dulac, F.: Wet deposition in a global size-dependent aerosol transport model. 2. Influence of the scavenging scheme on $210 \mathrm{~Pb}$ vertical profiles, surface concentrations, and deposition, J. Geophys. Res., 103(D22), 28 875-28 891, 1998.

Hänel, G.: The properties of atmospheric aerosols as functions of 
the relative humidity at thermodynamic equilibrium with the surrounding moist air, Adv. Geophys., 19, 73-188, 1976.

Hass, H., Van Loon, M., Kessler, C., Stern, R., Matthijsen, J., Sauter, F., Zlatev, Z., Langgner, J., Foltescu, V., and Schaap, M.: Aerosol Modeling: Results and Intercomparison from European Regional-scale Modeling Systems, A contribution to the EUROTRAC-2 subproject GLOREAM, 2003.

Hauglustaine, D. A., Hourdin, F., Jourdain, L., Filiberti, M.-A., Walters, S., Lamarque, J.-F., and Holland, E. A.: Interactive chemistry in the Laboratoire de Meteorologie Dynamique general circulation model: Description and background tropospheric chemistry evaluation, J. Geophys. Res., 109, D04314, doi:10.1029/2003JD003957, 2004.

Hegg, D. A., Livingston, J., Hobbs, P. V., Novakov, T., and Russell, P.: Chemical apportionment of aerosol column optical depth off the mid-Atlantic coast of the United States, J. Geophys. Res., 102(D21), 25 293-25 303, 1997.

Henning, S., Weingartner, E., Schwikowski, M., Gaggeler, H. W., Gehrig, R., Hinz, K. P., Trimborn, A., Spengler, B., and Baltensperger, U.: Seasonal variation of water-soluble ions of the aerosol at the high-alpine site Jungfraujoch (3580 m asl), J. Geophys. Res., 108(D1), 4030, doi:10.1029/2002JD002439, 2003.

Hering, S., Eldering, A., and Seinfeld, J. H.: Bimodal character of accumulation mode aerosol mass distributions in Southern California, Atmos. Environ., 31, 1-11, 1997.

Hodzic, A., Chepfer, H., Vautard, R., Chazette, P., Beekmann, M., Bessagnet, B., Chatenet, B., Cuesta, J., Drobinski, P., Goloub, P., Haeffelin, M., and Morille, Y.: Comparison of aerosol chemistry transport model simulations with lidar and Sun photometer observations at a site near Paris, J. Geophys. Res., 109(D23), D23201, doi:10.1029/2004JD004735, 2004.

Hodzic, A., Vautard, R., Bessagnet, B., Lattuati, M., and Moreto, F.: Long-term urban aerosol simulation versus routine particulate matter observations, Atmos. Environ., 39(32), 5851-5864, 2005.

Hodzic, A., Vautard, R., Chepfer, H., Goloub, P., Menut, L., Chazette, P., Deuzé, J. L., Apituley, A., and Couvert, P.: Evolution of aerosol optical thickness over Europe during the August 2003 heat wave as seen from POLDER data and CHIMERE model simulations, Atmos. Chem. Phys., 6, 1853-1864, $2006 \mathrm{a}$.

Hodzic, A., Bessagnet, B., and Vautard, R.: A model evaluation of coarse-mode nitrate heterogeneous formation on dust particles, Atmos. Environ., 40(22), 4158-4171, 2006b.

Jaffrezo, J.-L., Davidson, C. I., Legrand, M., and Dibb, J. E.: Sulfate and MSA in the air snow on the Greenland Ice Sheet, J. Geophys. Res., 99(D1), 1241-1254, 1994.

Kahnert, M., Tarrason, L., Amann, M., et al.: Transboundary Particulate Matter in Europe: Status Report 2003, EMEP Report 4/2003.

Kyle, A. D., Woodruff, T. J., Buffler, P. A., and Davis, D. L.: Use of an index to reflect the aggregate burden of long-term exposure to criteria air pollutants in the United States, Environmental Health Perspectives, 110, 95-102, 2002.

Krishnamurti, T. N., Jha, B., Prospero, J., Jayaraman, A., and Ramanathan, V.: Aerosol and pollutant transport and their impact on radiative forcing over the tropical Indian Ocean during the January-February 1996 pre-INDOEX cruise, Tellus B-Chemical and Physical Meteorology, 50(5), 521-542, 1998.

Kulmala, M., Laaksonen, A., and Pirjola, L.: Parameterization for sulfuric acid/water nucleation rates, J. Geophys. Res., 103(D7),
8301-8307, 1998.

Lonati, G., Giugliano, M., Butelli, P., Romele, L., and Tardivo, R.: Major chemical components of PM2.5 in Milan (Italy), Atmos. Environ., 39(10), 1925-1934, 2005.

Menut, L., Vautard, R., Flamant, C., Abonnel, C., Beekmann, M., Chazette, P., Flamant, P. H., Gombert, D., Guedalia, D., Kley, D., Lefebvre, M. P., Lossec, B., Martin, D., Megie, G., Perros, P., Sicard, M., and Toupance, G.: Measurements and modelling of atmospheric pollution over the Paris area: an overview of the ESQUIF Project, Ann. Geophys., 18(11), 1467-1481, 2000.

Nenes, A., Pilinis, C., and Pandis, S. N.: ISORROPIA: A new thermodynamic model for inorganic multicomponent atmospheric aerosols, Aquatic Geochem., 4, 123-152, 1998.

Pankow, J. F.: An absorption model of gas/particle partitioning of organic compounds in the atmosphere, Atmos. Environ., 28, 185-188, 1994.

Pope, C. A.: Review: epidemiological basis for particulate air pollution health standards, Aerosol Sci. Technol., 32, 4-14, 2000.

Putaud, J.-P., Van Dingenen, R., Dell' Acqua, A., Raes, F., Matta, E., Decesari, S., Facchini, M. C., Fuzzi, S.: Size-segregated aerosol mass closure and chemical composition in Monte Cimone (I) during MINATROC, Atmos. Chem. Phys., 4, 889-902, 2004, http://www.atmos-chem-phys.net/4/889/2004/.

Schaap, M., Spindler, G., Schulz, M., Acker, K., Maenhaut, W., Berner, A., Wieprecht, W., Streit, N., Muller, K., Bruggemann, E., Chi, X., Putaud, J. P., Hitzenberger, R., Puxbaum, H., Baltensperger, U., and ten Brink, H.: Artefacts in the sampling of nitrate studied in the "INTERCOMP" campaigns of EUROTRACAEROSOL, Atmos. Environ., 38, 6487-6496, 2004a.

Schaap, M., van Loon, M., ten Brink, H. M., Dentener, F. J., and Builtjes, P. J. H.: Secondary inorganic aerosol simulations for Europe with special attention to nitrate, Atmos. Chem. Phys., 4, 857-874, 2004b.

Schmidt, H., Derognat, C., Vautard, R., and Beekmann, M.: A comparison of simulated and observed ozone mixing ratios for the summer of 1998 in Western Europe, Atmos. Environ., 35(36), 6277-6297, 2001.

Seigneur, C.: Current status of air quality models for particulate matter, J. Air Waste Manage. Assoc., 51(11), 1508-1521, 2001.

Seinfeld, J. H. and Pandis, S. N.: Atmospheric Chemistry and Physics, John Wiley \& Sons, New York, 1998.

Tan, Q., Hang, Y., and Chameides, W. L.: Budget and export of anthropogenic SOx from East Asia during continental outflow conditions, J. Geophys. Res., 107(D13), doi:10.1029/2001JD000769, 2002.

Tsyro, S.: First estimates of the effect of aerosol dynamics in the calculation of $\mathrm{PM}_{10}$ and $\mathrm{PM}_{2.5}$, EMEP Report (http://www. emep.int), 2002.

Turpin, B. J. and Huntzicker, J. J.: Identification of secondary organic aerosol episodes and quantitation of primary and secondary organic aerosol concentrations during SCAQS, Atmos. Environ., 29, 3527-3544, 1995.

Turpin, B. J., Saxena, P., and Andrews, E.: Measuring and simulating particulate organics in the atmosphere: problems and prospects, Atmos. Environ., 34(18), 2983-3013, 2000.

Van Loon, M.: Model intercomparison in the framework of the review of the unified EMEP model, Technical report TNO-MEP R2004/282, Apeldoorn, the Netherlands, 2004.

Vautard, R., Martin, D., Beekmann, M., Drobinski, P., Friedrich, 
R., Jaubertie, A., Kley, D., Lattuati, M., Moral, P., Neininger, B., and Theloke, J.: Paris emission inventory diagnostics from ESQUIF airborne measurements and a chemistry transport model, J. Geophys. Res., 108(D17), 8564, doi:10.1029/2002JD002797, 2003a.

Vautard, R., Menut, L., Beekmann, M., Chazette, P., Flamant, P. H., Gombert, D., Guedalia, D., Kley, D., Lefebvre, M. P., Martin, D., Megie, G., Perros, P., and Toupance, G.: A synthesis of the Air Pollution over the Paris Region (ESQUIF) field campaign, J. Geophys. Res., 108(D17), 8558, doi:10.1029/2003JD003380, 2003b.

Vautard, R., Bessagnet, B., Chin, M., and Menut, L.: On the contribution of natural Aeolian sources to particulate matter concentrations in Europe: Testing hypotheses with a modelling approach, Atmos. Environ., 39(18), 3291-3303, 2005.
Verwer, J.: Gauss-seidel iterations for stiff odes from chemical kinetics, SIAM Journal of Scientific Computing, 15, 1243-1250, 1994.

Zhang, Y., Pun, B., Vijayaraghavan, K., Wu, S. Y., Seigneur, C., Pandis, S. N., Jacobson, M. Z., Nenes, A., and Seinfeld, J. H.: Development and application of the model of aerosol dynamics, reaction, ionization, and dissolution (MADRID), J. Geophys. Res., 109(D1), D01202, doi:10.1029/2003JD003501, 2004.

Zhuang, H., Chan, C. K., Fang, M., and Wexler, A. S.: Size distributions of particulate sulfate, nitrate, and ammonium at a coastal site in Hong Kong, Atmos. Environ., 33(6), 843-853, 1999. 